\title{
Head and Neck Cancers, Version 2.2020
}

David G. Pfister, MD,*; Sharon Spencer, MD²,*; David Adelstein, MD³,*; Douglas Adkins, MD ${ }^{4, \star} ;$ Yoshimi Anzai, MD, MPH ${ }^{5}$; David M. Brizel, MD; ; Justine Y. Bruce, MD; Paul M. Busse, MD, PhD ${ }^{8}$; Jimmy J. Caudell, MD, PhD, ${ }^{9} ;$ Anthony J. Cmelak, MD ${ }^{10}$; A. Dimitrios Colevas, MD ${ }^{11, \star}$; David W. Eisele, MD ${ }^{12, \star}$; Moon Fenton, MD, PhD ${ }^{13}$; Robert L. Foote, MD ${ }^{14}$; Thomas Galloway, MD ${ }^{15}$; Maura L. Gillison, MD, PhD ${ }^{16, *}$; Robert I. Haddad, MD ${ }^{17, \star}$; Wesley L. Hicks Jr., MD ${ }^{18}$; Ying J. Hitchcock, MD ${ }^{5}$;

Antonio Jimeno, MD, PhD ${ }^{19}$; Debra Leizman, MD; Ellie Maghami, MD ${ }^{20, *}$; Loren K. Mell, MD ${ }^{21}$; Bharat B. Mittal, MD ${ }^{22}$; Harlan A. Pinto, MD ${ }^{11}$; John A. Ridge, MD, PhD ${ }^{15}$; James W. Rocco, MD, PhD ${ }^{23}$; Cristina P. Rodriguez, MD ${ }^{24, \star}$; Jatin P. Shah, MD, PhD ${ }^{1, \star}$; Randal S. Weber, MD ${ }^{16, *}$; Gregory Weinstein, MD ${ }^{25}$; Matthew Witek, MD; Frank Worden, MD ${ }^{26, *}$; Sue S. Yom, MD, PhD $27, \star$; Weining Zhen, MD ${ }^{28}$; Jennifer L. Burns ${ }^{29, \star}$; and Susan D. Darlow, PhD ${ }^{29, \star}$

\section{ABSTRACT}

Treatment is complex for patients with head and neck (H\&N) cancers with specific site of disease, stage, and pathologic findings guiding treatment decision-making. Treatment planning for $\mathrm{H} \& \mathrm{~N}$ cancers involves a multidisciplinary team of experts. This article describes supportive care recommendations in the NCCN Guidelines for Head and Neck Cancers, as well as the rationale supporting a new section on imaging recommendations for patients with H\&N cancers. This article also describes updates to treatment recommendations for patients with very advanced $\mathrm{H} \& \mathrm{~N}$ cancers and salivary gland tumors, specifically systemic therapy recommendations.

J Natl Compr Canc Netw 2020;18(7):873-898 doi: $10.6004 /$ jnccn.2020.0031

\footnotetext{
${ }^{1}$ Memorial Sloan Kettering Cancer Center; ${ }^{2} \mathrm{O}$ 'Neal Comprehensive Cancer Center at UAB; ${ }^{3}$ Case Comprehensive Cancer Center/University Hospitals Seidman Cancer Center and Cleveland Clinic Taussig Cancer Institute; ${ }^{4}$ Siteman Cancer Center at Barnes-Jewish Hospital and Washington University School of Medicine; ${ }^{5}$ Huntsman Cancer Institute at the University of Utah; ${ }^{6}$ Duke Cancer Institute; ${ }^{7}$ University of Wisconsin Carbone Cancer Center;

${ }^{8}$ Massachusetts General Hospital Cancer Center; ${ }^{9}$ Moffitt Cancer Center;

${ }^{10}$ Vanderbilt-Ingram Cancer Center; ${ }^{11}$ Stanford Cancer Institute; ${ }^{12}$ The Sidney Kimmel Comprehensive Cancer Center at Johns Hopkins; ${ }^{13}$ The University of Tennessee Health Science Center; ${ }^{14}$ Mayo Clinic Cancer Center; ${ }^{15}$ Fox Chase Cancer Center; ${ }^{16}$ The University of Texas MD Anderson Cancer Center; ${ }^{17}$ DanaFarber/Brigham and Women's Cancer Center; ${ }^{18}$ Roswell Park Comprehensive Cancer Center; ${ }^{19}$ University of Colorado Cancer Center; ${ }^{20}$ City of Hope National Medical Center; ${ }^{21}$ UC San Diego Moores Cancer Center; ${ }^{22}$ Robert H. Lurie Comprehensive Cancer Center of Northwestern University; ${ }^{23}$ The Ohio State University Comprehensive Cancer Center - James Cancer Hospital and Solove Research Institute; ${ }^{24}$ Fred Hutchinson Cancer Research Center/Seattle Cancer Care Alliance; ${ }^{25}$ Abramson Cancer Center at the University of Pennsylvania;

${ }^{26}$ University of Michigan Rogel Cancer Center; ${ }^{27}$ UCSF Helen Diller Family

Comprehensive Cancer Center; ${ }^{28}$ Fred \& Pamela Buffett Cancer Center; and

${ }^{29}$ National Comprehensive Cancer Network
}

*Discussion Writing Committee Member.

\section{NCCN CATEGORIES OF EVIDENCE AND CONSENSUS}

Category 1: Based upon high-level evidence, there is uniform NCCN consensus that the intervention is appropriate.

Category 2A: Based upon lower-level evidence, there is uniform NCCN consensus that the intervention is appropriate.

Category 2B: Based upon lower-level evidence, there is NCCN consensus that the intervention is appropriate.

Category 3: Based upon any level of evidence, there is major $\mathrm{NCCN}$ disagreement that the intervention is appropriate.

All recommendations are category $2 \mathrm{~A}$ unless otherwise noted.

Clinical trials: NCCN believes that the best management of any patient with cancer is in a clinical trial. Participation in clinical trials is especially encouraged.

\section{PLEASE NOTE}

The NCCN Clinical Practice Guidelines in Oncology (NCCN Guidelines ${ }^{\circledR}$ ) are a statement of evidence and consensus of the authors regarding their views of currently accepted approaches to treatment. Any clinician seeking to apply or consult the NCCN Guidelines is expected to use independent medical judgment in the context of individual clinical circumstances to determine any patient's care or treatment. The National Comprehensive Cancer Network ${ }^{\circledR}\left(\mathrm{NCCN}^{\circledR}\right)$ makes no representations or warranties of any kind regarding their content, use, or application and disclaims any responsibility for their application or use in any way.

The complete NCCN Guidelines for Head and Neck Cancers are not printed in this issue of JNCCN but can be accessed online at NCCN.org.

(c) National Comprehensive Cancer Network, Inc. 2020. All rights reserved. The NCCN Guidelines and the illustrations herein may not be reproduced in any form without the express written permission of NCCN.

\section{Disclosures for the NCCN Head and Neck Cancers Panel}

At the beginning of each NCCN Guidelines Panel meeting, panel members review all potential conflicts of interest. NCCN, in keeping with its commitment to public transparency, publishes these disclosures for panel members, staff, and NCCN itself.

Individual disclosures for the NCCN Head and Neck Cancers Panel members can be found on page 898. (The most recent version of these guidelines and accompanying disclosures are available at NCCN.org.)

The complete and most recent version of these guidelines is available free of charge at NCCN.org. 


\section{Very Advanced Head and Neck Cancer}
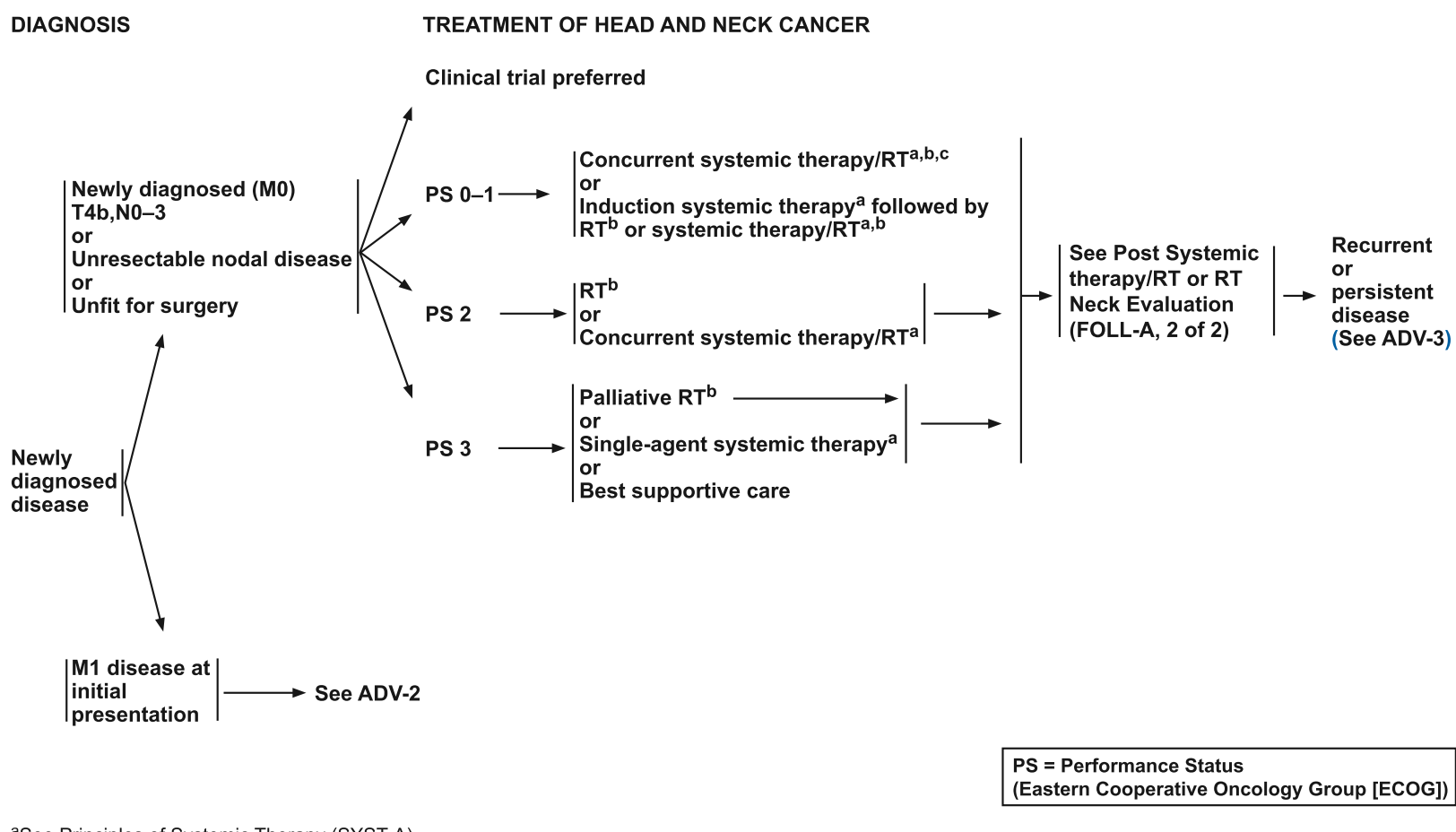

aSee Principles of Systemic Therapy (SYST-A)

cWhen using concurrent systemic therapy/RT, the preferred agent is cisplatin (category 1). See Principles of Systemic Therapy (SYST-A).

\section{Overview}

The NCCN Guidelines for Head and Neck Cancers address tumors arising in the lip, oral cavity, pharynx, larynx, and paranasal sinuses; occult primary cancer, salivary gland cancer, and mucosal melanoma are also addressed. ${ }^{1,2}$ In 2020, it is estimated that about 65,630 new cases of oral cavity, pharyngeal, and laryngeal cancers will occur, which account for about $3.6 \%$ of new cancer cases in the United States. ${ }^{3}$ An estimated 14,500 deaths from head and neck $(\mathrm{H} \& \mathrm{~N})$ cancers will occur during the same time period. ${ }^{4}$ Squamous cell carcinoma or a variant is the histologic type in more than $90 \%$ of these tumors.

Alcohol and tobacco abuse are the most common etiologic factors in cancers of the oral cavity, hypopharynx, larynx, and HPV-unrelated oropharynx. Because the entire aerodigestive tract epithelium may be exposed to these carcinogens, patients with $\mathrm{H} \& \mathrm{~N}$ cancers are at risk for harboring synchronous primary tumors and developing second primary neoplasms of the $H \& N$, lung, esophagus, and other sites that share these risk factors. The attributable fraction for HPV in newly diagnosed oropharyngeal cancer is estimated at $60 \%-70 \%$ in the United States and parts of the European Union. ${ }^{5-9}$ In the case of nasopharyngeal carcinoma, $95 \%$ of cases in endemic regions are of differentiated or undifferentiated nonkeratinizing type, which is very closely associated with infection with Epstein-Barr virus. ${ }^{10-12}$ In the United States, however, keratinizing types comprise upwards of $40 \%$ based on SEER data, although both keratinizing and nonkeratinizing types are found in all ethnicities. ${ }^{13}$

Stage at diagnosis predicts survival rates and guides management in patients with H\&N cancers. In general, stage I or II disease defines a relatively small primary tumor with no nodal involvement. Stage III or IV cancers generally include larger primary tumors, which may invade underlying structures and/or spread to regional nodes. Distant metastases are less common at presentation than in lung and esophagus cancers. More advanced TNM stages are associated with worse survival. The 8th edition of the AJCC Cancer Staging Manual included new staging criteria for HPV-related oropharyngeal 


\section{Very Advanced Head and Neck Cancer} DIAGNOSIS

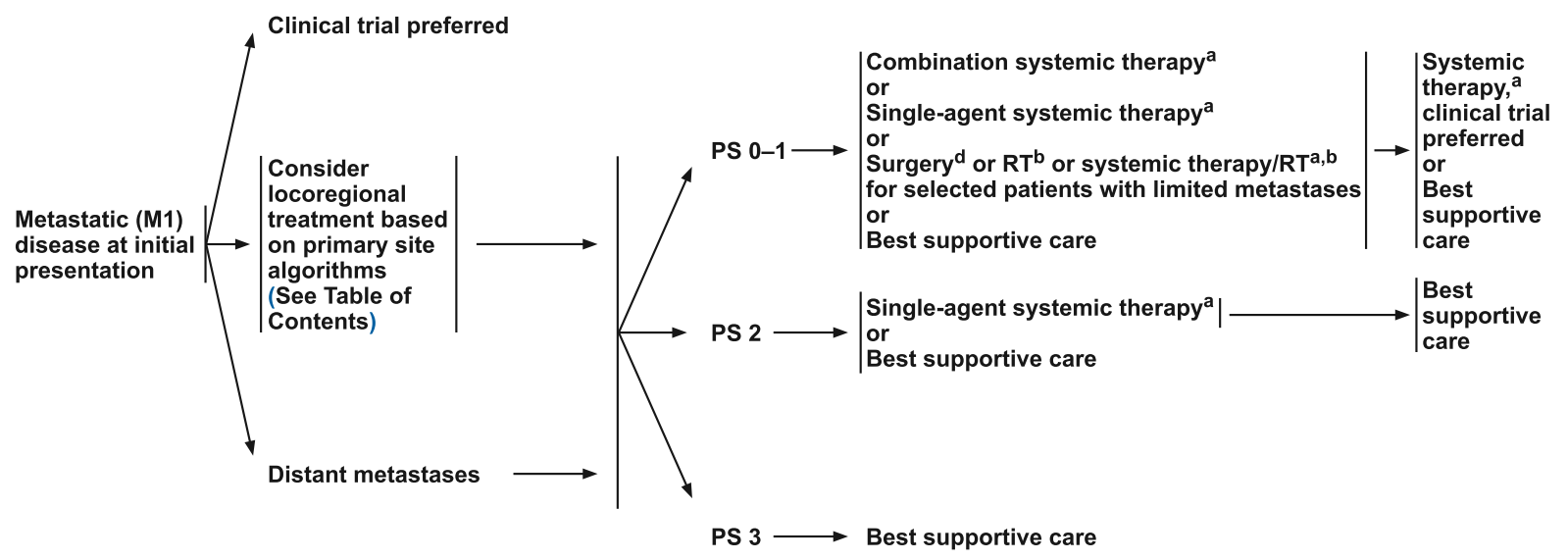

*Available online, in these guidelines, at NCCN.org

cancer. ${ }^{14}$ In these staging criteria, nodal disease could be considered stage I if the nodes are ipsilateral and none larger than $6 \mathrm{~cm}$. Staging of nasopharyngeal cancer is also different from other $H \& N$ cancer sites, since the primary treatment of this disease is radiation therapy (RT) with or without chemotherapy. ${ }^{14}$ Nasopharyngeal cancers are generally not resected; therefore, the staging for this cancer does not include pathologic classification.

\section{Management Approaches}

The specific site of disease, stage, and pathologic findings guide treatment (eg, the appropriate surgical procedure, radiation targets, dose and fractionation of radiation, indications for systemic therapy). Single-modality treatment with surgery or RT is generally recommended for the approximately $30 \%-40 \%$ of patients who present with early-stage disease (stage I or II). Surgery and RT result in similar survival for many $H \& N$ cancers, but surgery is usually preferred for oral cavity and paranasal sinus cancers, while RT with or without chemotherapy is nearly always preferred for all stages of nasopharyngeal carcinoma. The choice of surgery or RT is often based on local institutional expertise and/or perceived relative morbidity of these treatment options. With evolving techniques of RT and less invasive surgery, as well as improving supportive care for patients receiving systemic therapy, morbidity is also a moving target. Combined modality therapy is generally recommended for the approximately $60 \%$ of patients with locally or regionally advanced disease at diagnosis. When chemotherapy is delivered with radiation, cisplatin is the preferred radiosensitizer.

Participation in clinical trials is a preferred or recommended treatment option in many situations. In formulating these NCCN Guidelines, panel members have tried to make them evidence-based while providing a statement of consensus as to the acceptable range of treatment options. In numerous population-based studies, patients treated at high-volume centers appear to have better outcomes relative to patients treated at low-volume centers. ${ }^{15-19}$ 


\section{Very Advanced Head and Neck Cancer}

DIAGNOSIS

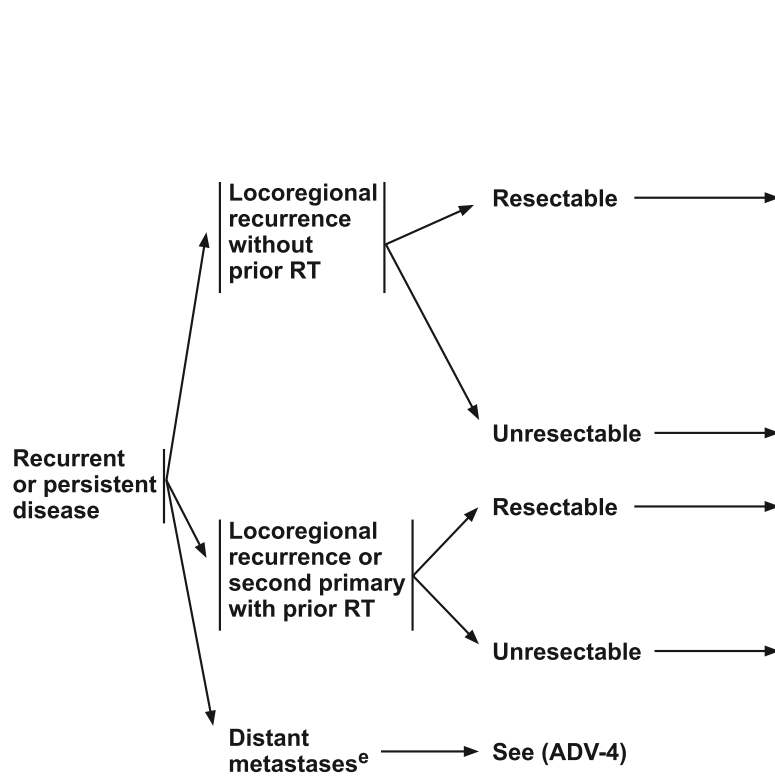

asee Principles of Systemic Therapy (SYST-A).

bSee Principles of Radiation Therapy (ADV-A).

cWhen using concurrent systemic therapy/RT, the preferred agent is cisplatin (category 1). See Principles of Systemic Therapy (SYST-A).

dSee Principles of Surgery (SURG-A*).

${ }^{e}$ Consider palliative RT as clinically indicated (eg, bone metastases). (See RAD-A*).

*Available online, in these guidelines, at NCCN.org
TREATMENT OF HEAD AND NECK CANCER

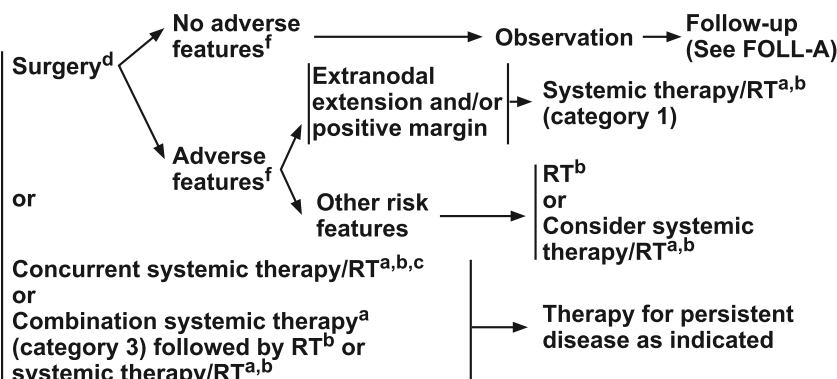

See Treatment of Very Advanced Head and Neck Cancer (ADV-1)

Surgery $^{d} \pm$ postoperative reirradiation ${ }^{b, g}$ or systemic therapy $/ R T,{ }^{a, b}$ clinical trial preferred

Reirradiation ${ }^{\mathrm{b}} \pm$ systemic therapy, ${ }^{\mathrm{a}}$ clinical trial preferred or

ystemic therapy ${ }^{a}$ (see ADV-4)

or

Best supportive care

${ }^{f}$ Adverse features: extranodal extension, positive margins, close margins, pT3 or $\mathrm{pT} 4$ primary, $\mathrm{pN} 2$ or $\mathrm{pN} 3$ nodal disease, perineural invasion, vascular invasion, lymphatic invasion (See Discussion).

gReirradiation should be limited to a highly select subset of patients (Janot F, de Raucourt D, Benhamou E, et al. Randomized trial of postoperative reirradiation combined with chemotherapy after salvage surgery compared with salvage surgery alone in head and neck carcinoma. J Clin Oncol 2008;26:5518-5523).

\section{Multidisciplinary Team Involvement}

The initial evaluation and development of a plan for treating the patient with $\mathrm{H} \& \mathrm{~N}$ cancer requires a multidisciplinary team of health care providers with expertise in caring for these patients. ${ }^{20,21}$ Similarly, managing and preventing sequelae after surgery, RT, and systemic therapy (eg, pain, lymphedema and muscle spasm of the neck, xerostomia, dysphagia, speech and swallowing problems, depression) require professionals familiar with the disease. ${ }^{22-24}$ Follow-up for these sequelae should include a comprehensive $H \& N$ examination and supportive care and rehabilitation (see "Follow-Up Recommendations," page 883).$^{20}$ Adequate nutritional support can help to prevent severe weight loss in patients receiving treatment of $\mathrm{H} \& \mathrm{~N}$ cancers; therefore, patients should be encouraged to see a registered dietitian at diagnosis and as needed during and after treatment (see "Principles of Nutrition: Management and Supportive Care," in these guidelines at NCCN.org and "Principles of Nutrition and Supportive Care," page 883). ${ }^{25}$ Dental care to prevent and treat RT effects should be provided (see "Principles of Dental Evaluation and Management," in these guidelines at NCCN.org and page 886). Evaluation by a speech-language/swallowing therapist before and after treatment is recommended. Patients are at risk for depression from $\mathrm{H} \& \mathrm{~N}$ cancer and its sequelae, so screening for depression is advised (see the NCCN Guidelines for Distress Management, available at NCCN.org).$^{26-29}$ Fertility/reproductive counseling should be offered to younger patients (see the NCCN Guidelines for Adolescent and Young Adult Oncology, available at NCCN.org). Specific components of patient support and follow-up are listed in the algorithm (see "Team Approach," in these guidelines at NCCN.org). Panel members also recommend referring to the NCCN Guidelines for Palliative Care and Adult Cancer Pain as needed (available at NCCN.org).

Tobacco use is associated with at least $30 \%$ of cancer deaths. ${ }^{30}$ Therefore, patients' tobacco use history should be assessed. Patients should be encouraged to stop smoking (and remain abstinent) and to modify alcohol consumption if excessive because these habits decrease 


\section{Very Advanced Head and Neck Cancer} DIAGNOSIS

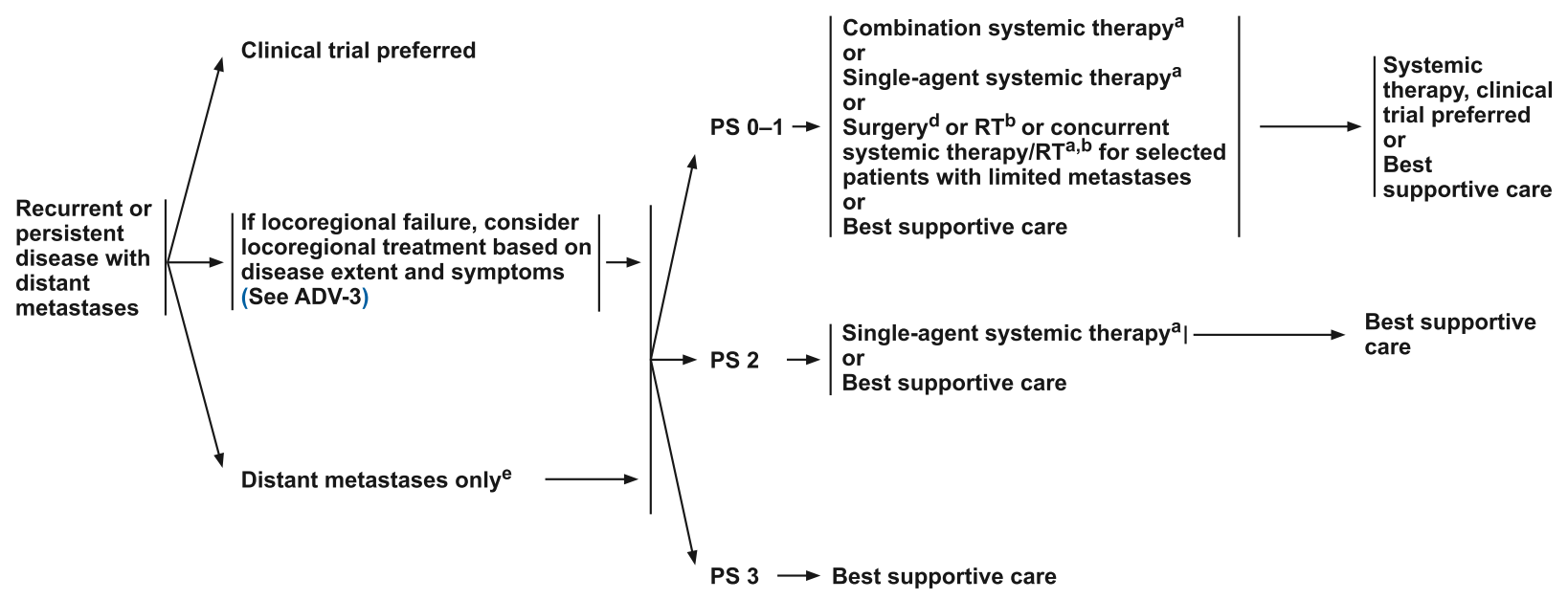

asee Principles of Systemic Therapy (SYST-A).

bSee Principles of Radiation Therapy (ADV-A).

dSee Principles of Surgery (SURG-A*)

Consider palliative RT as clinically indicated (eg, bone metastases). (See RAD- $A^{*}$.

*Available online, in these guidelines, at NCCN.org

Version 22020 06/09/20 @ National Comprehensive Cancer Network Inc. 2020 . All rights reseved

The NCCN Guidelines ${ }^{\otimes}$ and this illustration may not be reproduced in any form without the express written permission of NCCN.

the efficacy of treatment and adversely affect other health outcomes. ${ }^{31,32}$ Information on smoking cessation resources and support can be found in the NCCN Guidelines for Smoking Cessation (available at NCCN.org).

\section{Resectable Versus Unresectable Disease}

The term unresectable has resisted formal definition by $\mathrm{H} \& \mathrm{~N}$ cancer specialists. The experience of the surgeon and the support available from reconstructive surgeons, physiatrists, and prosthodontists often strongly influence recommendations, especially in institutions where only a few patients with locally advanced H\&N cancers are treated. The NCCN Member Institutions have teams experienced in the treatment of $\mathrm{H} \& \mathrm{~N}$ cancers and maintain the multidisciplinary infrastructure needed for reconstruction and rehabilitation. A patient's cancer is deemed unresectable if $\mathrm{H} \& \mathrm{~N}$ surgeons at NCCN Member Institutions do not think they can remove the gross tumor on anatomic grounds or if local control is unlikely to be achieved with the use of surgery (even with the addition of RT to the treatment approach). Typically, these unresectable tumors densely involve the cervical vertebrae, brachial plexus, deep muscles of the neck, or carotid artery (see "Principles of Surgery," in these guidelines at NCCN.org). Tumor involvement of certain sites is associated with poor prognosis (ie, direct extension of neck disease to involve the external skin; direct extension to mediastinal structures, prevertebral fascia, or cervical vertebrae).

Unresectable tumors should be distinguished from inoperable tumors in those patients whose constitutional state precludes an operation (even if the cancer could be readily resected with few sequelae). Additionally, a subgroup of patients will decline surgical management, but their tumors should not be deemed unresectable. In some patients, adequate reconstructive options may be lacking; therefore, the patient's disease is considered functionally unresectable. Examples include bilateral orbital exenteration or exenteration in the only seeing eye, extensive mandibular resection without reconstruction options, or total pharyngectomy when reconstitution of the alimentary tract is not feasible. 


\section{Salivary Gland Tumors}

CLINICAL WORKUP PRESENTATION

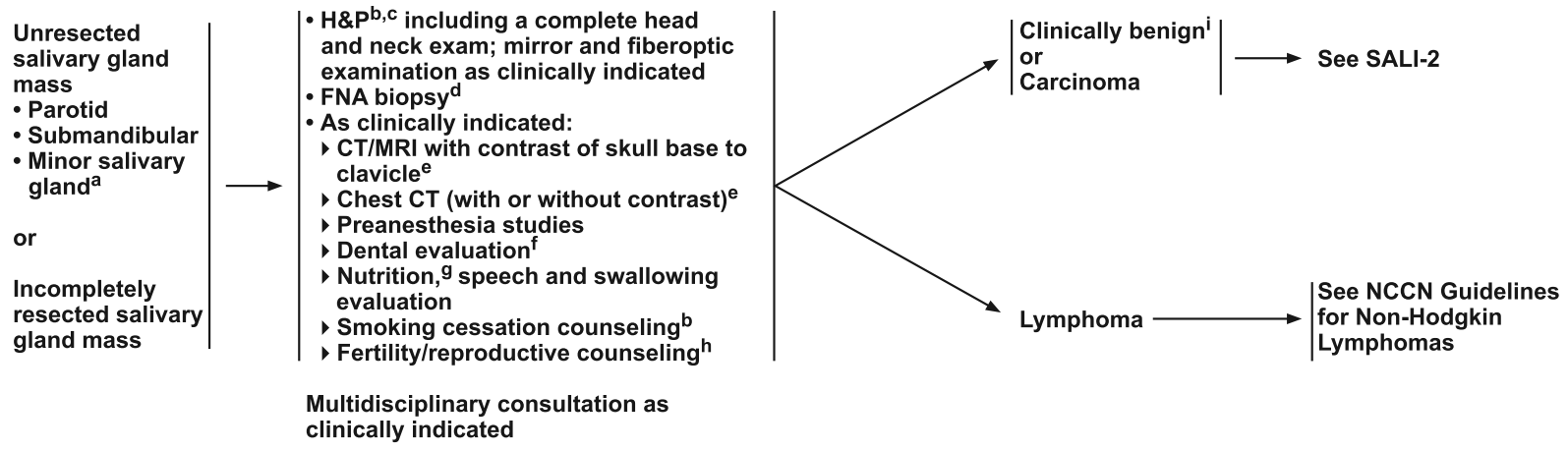

a Site and stage determine therapeutic approaches.

b H\&P should include documentation and quantification (pack years smoked) of tobacco use history. All current smokers should be advised to quit smoking, and former smokers should be advised to remain abstinent from smoking. For additional cessation support, refer to the Patient/Provider Smoking Cessation Resources in the NCCN Guidelines for Smoking Cessation ${ }^{\dagger}$

c Screen for depression (See NCCN Guidelines for Distress Management ${ }^{\dagger}$ ).

d Image-guided (US or CT) needle biopsy of cystic neck nodes may offer better

diagnostic yield than FNA by palpation alone for initial diagnosis in this setting.

diagnostic yield than FNA by palpation
e See Principles of Imaging (IMG-A* ${ }^{*}$.

${ }^{f}$ See Principles of Dental Evaluation and Management (DENT-A*).

$g$ See Principles of Nutrition: Management and Supportive Care

$($ NUTR-A*).

$h$ See fertility and reproductive endocrine considerations in the NCCN

Guidelines for Adolescent and Young Adult (AYA) Oncology ${ }^{\dagger}$.

Characteristics of a benign tumor include mobile superficial lobe, slow

growth, painless, $V$ and/or VII intact, and no neck nodes.

*Available online, in these guidelines, at NCCN.org. †To view the most recent version of these guidelines, visit NCCN.org.

Version 22020 06/09/20 @ Nation

The NCCN Guidelines and this illustration may not be reproduced in any form without the express written permission of NCCN.

SALI-1

Though these are rare occurrences, the impact on quality of life and the need for continual supportive care are significant and open ended. Although local and regional disease may be surgically treatable, patients with distant metastases are usually treated as though the primary tumor was unresectable. Thus, patient choice or physician expectations regarding cure and morbidity will influence or determine treatment. Patients with resectable tumors who can also be adequately treated without surgery represent a very important group. Definitive treatment with RT alone or RT combined with systemic therapy may represent equivalent or preferable approaches to surgery in these individuals. Although such patients may not undergo surgery, their tumors should not be labeled as unresectable. Their disease is usually far less extensive than those with disease that truly cannot be removed.

\section{Comorbidity and Quality of Life}

\section{Comorbidity}

Comorbidity refers to the presence of concomitant disease (in addition to $\mathrm{H} \& \mathrm{~N}$ cancers) that may affect diagnosis, treatment, and prognosis. ${ }^{33,34}$ Documentation of comorbidity is important to facilitate optimal treatment selection. Comorbidity is known to be a strong independent predictor for mortality in patients with $\mathrm{H} \& \mathrm{~N}$ cancers, ${ }^{35-38}$ and comorbidity also influences costs of care, utilization, and quality of life. ${ }^{39-41}$ Traditional indices of comorbidity include the Charlson Comorbidity Index ${ }^{42}$ and the Kaplan-Feinstein Index and its modifications. ${ }^{34,43}$ The Adult Comorbidity Evaluation-27 (ACE-27) is a validated instrument for assessing comorbidity in numerous cancer types including $\mathrm{H} \& \mathrm{~N}$ cancers. ${ }^{44}$ An important consideration when interpreting published clinical trial data are the applicability of the results to patients with significant comorbidities, who may have been ineligible/excluded from such studies.

\section{Quality of Life}

Health-related quality-of-life issues are important in $\mathrm{H} \& \mathrm{~N}$ cancers. These tumors affect basic physiologic functions (ie, the ability to chew, swallow, and breathe), the senses (ie, taste, smell, hearing), and uniquely human 


\section{Salivary Gland Tumors}

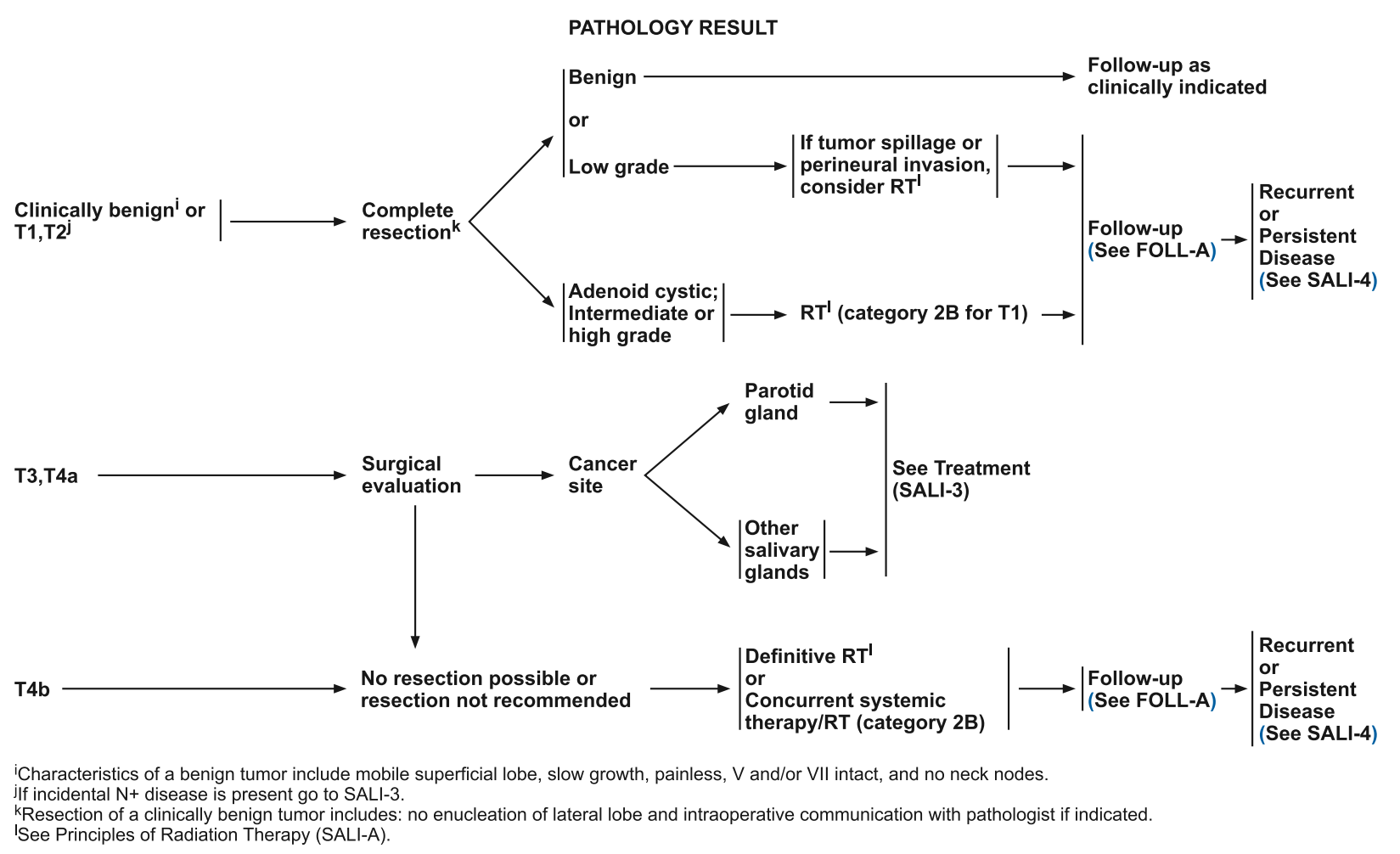

Version 2.2020, 06/09/20 ๑ National Comprehensive Cancer Network, Inc. 2020. All rights reserved

Version $2.2020,06 / 09 / 20 \odot$ National Comprehensive Cancer Network, Inc. 2020. All rights reserved.
The NCCN Guidelines ${ }^{\infty}$ and this illustration may not be reproduced in any form without the express written permission of NCCN.

SALI-2

characteristics (ie, appearance, voice). Health status describes an individual's physical, emotional, and social capabilities and limitations. Function and performance refer to how well an individual is able to perform important roles, tasks, or activities. Quality of life differs, because the central focus is on the value (determined by the patient alone) that individuals place on their health status and function. ${ }^{45}$

Patient-completed scales should be used to measure quality of life. ${ }^{46}$ Three validated and accepted measures for $H \& N$ cancer-specific issues are (1) the University of Washington Quality of Life Questionnaire ${ }^{47}$; 2) the European Organization for Research and Treatment of Cancer Quality of Life Questionnaire Head and Neck Module $^{48}$; and 3) the Functional Assessment of Cancer Therapy Head and Neck scale. ${ }^{49}$ The Performance Status Scale is a clinician-rated performance scale that is widely used for patients with $\mathrm{H} \& \mathrm{~N}$ cancers. ${ }^{50}$

\section{Imaging of Head and Neck Cancers}

Appropriate selection and use of imaging studies is crucial for proper management of patients with head and neck cancers. Initial imaging of the primary site is done with CT and/or MRI. MRI is generally preferred over CT in patients with cranial nerve symptoms or to evaluate cranial nerve involvement or tumors that encroach on the skull base. CT, conversely, is complementary to MRI for evaluation of bony erosion or cartilage invasion that may occur with some H\&N tumors. In patients with oral cavity cancer with bone involvement, MRI is needed to evaluate the extent of bone marrow invasion, while CT may be appropriate to evaluate cortical bone erosion or periosteal invasion. In patients with sinonasal tumors, MRI is useful for differentiating tumor extent from obstructed sinuses or secretions and to evaluate intracranial/dural involvement. Evaluation of lymph node metastases can be done with either CT or MRI, depending on the primary site, although both have lower accuracy as compared with FDG-PET/CT. ${ }^{51}$ Ultimately, choosing CT or MRI should be driven by the information desired; routinely ordering both may not be indicated.

There is evidence supporting the superiority of FDGPET/CT for detecting locoregional nodal and distant 


\section{Salivary Gland Tumors}

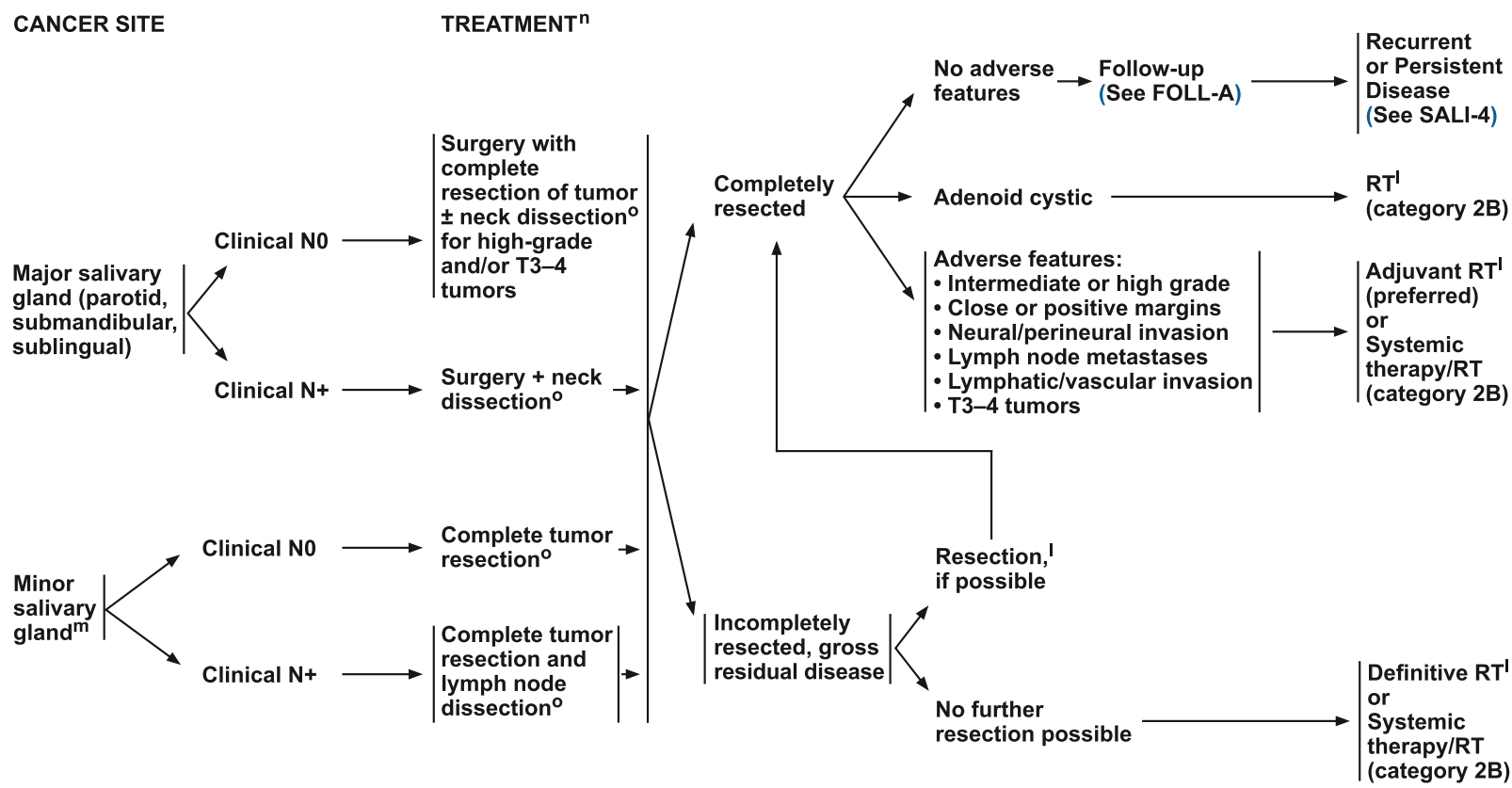

ISee Principles of Radiation Therapy (SALI-A).

mFor submandibular and sublingual gland tumors, complete gland and tumor resection is recommended.

nThe facial nerve should be preserved if possible; strongly consider referral to a specialized center with reconstructive expertise.

-See Principles of Surgery (SURG-A*).

${ }^{*}$ Available online, in these guidelines, at NCCN.org.

Version 2.2020, 06/09/20 ๑ National Comprehensive Cancer Network Inc. 2020. All rights reserved.

The NCCN Guidelines ${ }^{\circledast}$ and this illustration may not be reproduced in any form without the express written permission of NCCN.

SALI-3

metastases in patients with $\mathrm{H} \& \mathrm{~N}$ cancers. A metaanalysis including 24 studies with 1,270 patients with newly diagnosed $H \& N$ cancer showed sensitivity and specificity values of $91 \%$ and $87 \%$, respectively, for detection of regional nodal metastasis by FDG-PET/CT. ${ }^{52}$ In the analysis of per-neck-level data (13 studies), sensitivity was $84 \%$, compared with $63 \%$ for CT and/or MRI. Two metaanalyses have shown that sensitivity of FDG-PET/CT for detection of cervical lymph node involvement may be lower in patients with clinically node-negative $\mathrm{H} \& \mathrm{~N}$ squamous cell carcinoma (HNSCC) $(50 \%-58 \%) .{ }^{53,54}$ A metaanalysis including 10 studies showed that PET/CT had a sensitivity value of $89 \%$ and a specificity value of $98 \%$ for detecting bone metastases in patients with $H \& N$ cancer. ${ }^{55}$ In a prospective cohort study including 307 patients with oral, pharyngeal, or laryngeal cancer, FDGPET/CT detected distant metastasis more often than chest X-ray/H\&N MRI $(P<.001)$ and chest $\mathrm{CT} / \mathrm{H} \& \mathrm{~N}$ MRI $(P=.02) .{ }^{56}$ However, if there is concern about metastasis to a specific anatomic area, then directed CT or MRI may also be done (eg, contrast-enhanced chest CT to evaluate pulmonary metastases and/or mediastinal lymph node involvement; contrast-enhanced brain MRI for evaluation of brain metastases or skull base invasion). H\&N cancers rarely metastasize to the brain by a hematogenous route. Therefore, routinely ordering a full brain study as part of the initial imaging workup is not routine.

For patients who are dentulous and expected to receive postoperative RT, a panoramic dental X-ray should be completed before treatment as part of the dental evaluation (see "Principles of Dental Evaluation and Management," in these guidelines at NCCN.org and page 886).

\section{Short-Term Evaluation of Locoregionally}

\section{Advanced Disease}

Serial imaging may be part of response assessment. Which modality is best suited for follow-up should be carefully considered. It is unlikely all 3 modalities (CT, MRI, FDG PET/CT) will be needed, because this may add cost and inconvenience without significant added value. 


\section{Salivary Gland Tumors}

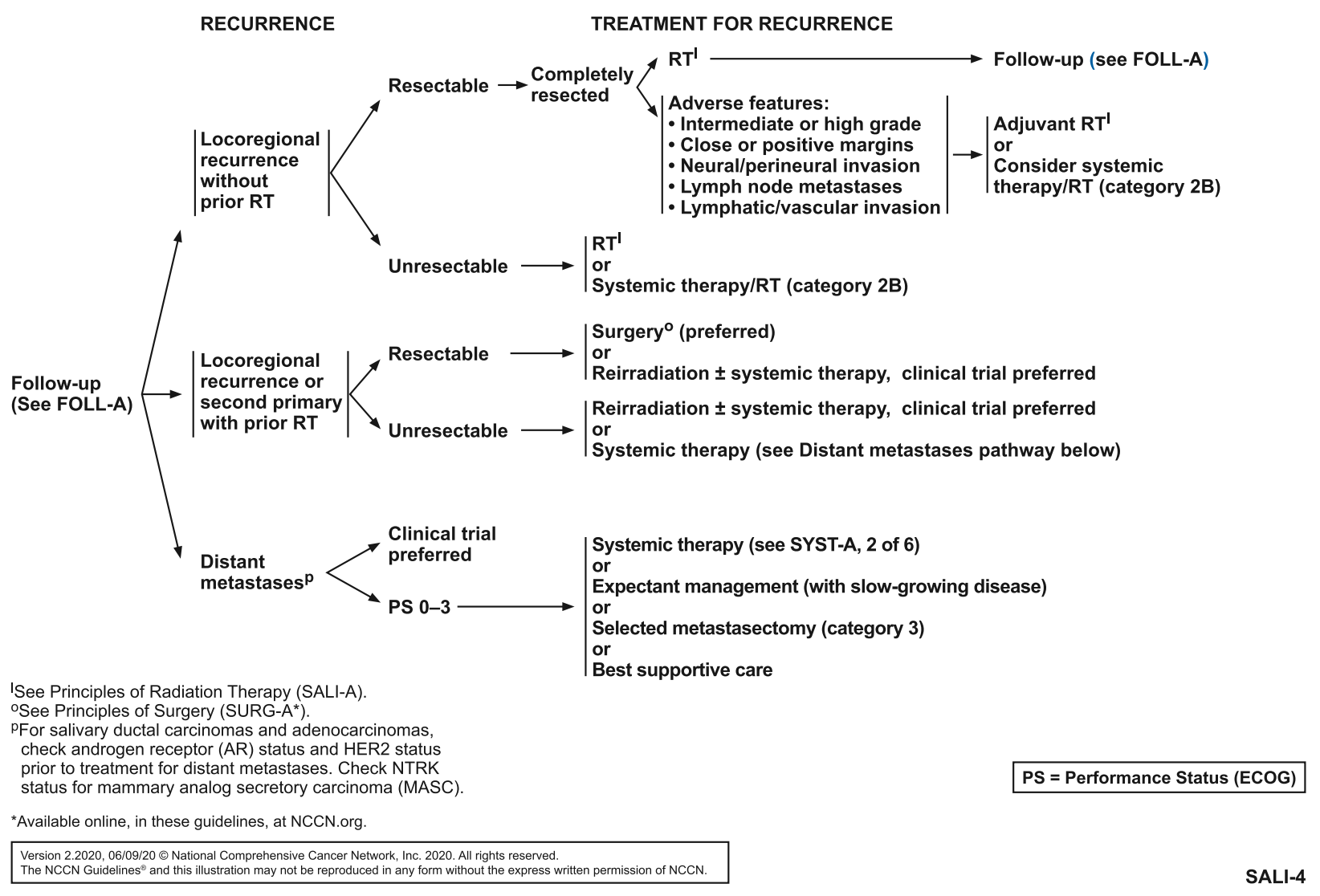

Patients treated with induction chemotherapy may receive imaging with CT or MRI after 2 or 3 cycles of induction. If there is high concern for distant metastasis, chest CT or FDG-PET/CT may be needed to evaluate whether to proceed to the planned definitive local therapy.

For patients with locoregionally advanced disease who have undergone surgery, postoperative imaging is recommended if there are signs of early recurrence, or for patients considered at high risk for early recurrence. This may be needed to evaluate whether to proceed to the planned adjuvant radiation-based therapy and/or to determine targets and dosing of radiation in case of unexpected recurrence. Patients with positive margins, advanced $\mathrm{T}$ or $\mathrm{N}$ stage, or oral cavity cancers are at particular risk for rapid recurrence after surgery. ${ }^{57}$

After definitive-intent treatment completion, the panel generally recommends imaging 3 or 4 months after the end of treatment, or as early as 4 to 8 weeks after definitive treatment if there is concern about an incomplete treatment response. Of note, proximity to recent treatment can complicate interpretation of radiographic studies, and communication with the interpreting radiologist is important to distinguish recurrent disease from posttreatment effect. PET scans can be particularly difficult to interpret at earlier time points.

Careful and regular follow-up examinations are recommended so that any local or regional recurrence is detected early. After RT-based treatment, evaluation with imaging (ie, CT and/or MRI with contrast, or preferably, FDG PET/CT) guides the use of neck dissection (see "Follow-Up Recommendations: Post Systemic Therapy/ RT or RT Neck Evaluation," FOLL-A 2 of 2, page 884). ${ }^{58-62}$ A meta-analysis including 5 studies with 359 patients showed that the sensitivity and specificity for FDG-PET/CT to detect local residual or recurrent disease were $81 \%$ and $90 \%$, respectively, and $73 \%$ and $89 \%$, respectively, for detection of nodal residual or recurrent disease. ${ }^{63}$ If PET/CT is used for follow-up, the first scan should be performed at a minimum of 12 weeks after treatment to reduce the false-positive rate. ${ }^{51,63-65} \mathrm{PET} / \mathrm{CT}$ surveillance in patients with advanced nodal disease who received 


\title{
Salivary Gland Tumors
}

\section{PRINCIPLES OF RADIATION THERAPY1,2,3}

\author{
DEFINITIVE: \\ RT Alone or Concurrent Systemic Therapy/RT \\ - Photon or photon/electron therapy or highly conformal radiation therapy techniques \\ - PTV: \\ High risk: Primary tumor and involved lymph nodes [this includes possible local subclinical infiltration at the primary and at the high-risk \\ level lymph node(s)] \\ $\diamond$ Fractionation: 66 Gy (2.0 Gy/fraction) to 70-70.2 Gy (1.8-2.0 Gy/fraction); daily Monday-Friday in 6-7 weeks ${ }^{4}$ \\ - Low to intermediate risk: Sites of suspected subclinical spread \\ $\diamond 44-50 \mathrm{~Gy}(2.0 \mathrm{~Gy} / \mathrm{fraction})$ to $54-63 \mathrm{~Gy}(1.6-1.8 \mathrm{~Gy} / \text { fraction })^{5}$ \\ POSTOPERATIVE RT: \\ RT Alone or Concurrent Systemic Therapy/RT \\ - Preferred interval between resection and postoperative RT is $\leq 6$ weeks \\ - Photon or photon/electron therapy \\ - PTV \\ - High risk: Adverse features such as positive margins (see SALI-3) \\ $\checkmark 60-66$ Gy $(2.0 \mathrm{~Gy} /$ fraction); daily Monday-Friday in 6-7 weeks \\ - Low to intermediate risk: Sites of suspected subclinical spread \\ $\checkmark$ 44-50 Gy (2.0 Gy/fraction) to 54-63 Gy (1.6-1.8 Gy/fraction) ${ }^{5}$ \\ Either IMRT or 3D conformal RT is recommended. Proton therapy can be considered when normal tissue constraints cannot be met by \\ photon-based therapy. \\ ${ }^{1}$ See Radiation Techniques (RAD-A*) and Discussion. \\ ${ }^{2}$ Neutron therapy was historically considered a promising solution for unresectable salivary gland cancers, but this therapy is currently offered at only one center in the \\ United States. Pfister DG, Spencer S, Brizel DM, et al. NCCN Head and Neck Cancers, Version 1.2015. J Natl Compr Canc Netw 2015:13:847-855. \\ 3 In general, the reirradiated population of head and neck cancer patients described in current literature represents a diverse but highly selected group of patients \\ treated in centers where there is a high level of expertise and systems in place for managing acute and long-term toxicities. When the goal of treatment is curative \\ and surgery is not an option, reirradiation strategies can be considered for patients who: develop locoregional failures or second primaries at $\geq 6$ months after the initial \\ radiotherapy; can receive additional doses of radiotherapy of at least $60 \mathrm{~Gy}$; and can tolerate concurrent chemotherapy. Organs at risk for toxicity should be carefully \\ analyzed through review of dose-volume histograms, and consideration for acceptable doses should be made on the basis of time interval since original radiotherapy, \\ anticipated volumes to be included, and patient's life expectancy. For reirradiation dosing, see Radiation Techniques (RAD- $\left.A^{*}\right)$. Proton therapy can be considered when \\ normal tissue constraints cannot be met by photon-based therapy. (Takiar V, Garden AS, Ma D, et al. Reirradiation of head and neck cancers with intensity modulated \\ radiation therapy: Outcomes and analyses. Int J Radiat Oncol Biol Phys 2016;95:1117-1131.) \\ ${ }^{4}$ For doses $>70 \mathrm{~Gy}$, some clinicians feel that the fractionation should be slightly modified (eg, $<2.0 \mathrm{~Gy} /$ fraction for at least some of the treatment) to minimize toxicity. An \\ additional 2-3 doses can be added depending on clinical circumstances. \\ ${ }^{5}$ Suggest 44-50 Gy in 3D conformal RT and sequentially planned IMRT or 54-63 Gy with IMRT dose painting technique (dependent on dose per fraction).
}

*Available online, in these guidelines, at NCCN.org

Version 2.2020, 06/09/20 @ National Comprehensive Cancer Network, Inc. 2020. All rights reserved.

The NCCN Guidelines ${ }^{\oplus}$ and this illustration may not be reproduced in any form without the express written permission of NCCN

systemic therapy/RT yielded a comparable survival rate and quality of life and may be more cost-effective, relative to planned neck dissection. ${ }^{66,67}$ Care should be taken regarding the timing and interpretation of PET studies, as false positive results may occur due to recent infection or treatment-related inflammation.

Note that a complete clinical response (ie, clinically negative) may be defined as no visible or palpable evidence of residual neck disease and no concerning findings on CT or MRI (ie, the absence of either focally abnormal lymph nodes or large nodes) ${ }^{58,68}$; a complete pathologic response requires pathologic confirmation. If a complete clinical response to RT-based treatment has been achieved, then the panel recommends observing the patient. ${ }^{58,68,69}$ In patients who have a clinically negative neck, PET/CT is associated with negative predictive values ranging from $97 \%$ to $100 \% .^{70-72}$ Panel members also concur that any patient with residual disease after RT-based treatment should be considered for surgical resection for refractory disease, including a neck dissection if indicated. ${ }^{58}$ If the residual, persistent, or progressing disease is unresectable, then these patients should receive systemic therapy and/or RT as described for recurrent or persistent disease in the algorithm (see "Recurrent or persistent disease," page 876 and "Recurrent or persistent disease with distant metastases", page 877). For patients with equivocal PET/CT scan results in the neck, a prospective study suggests that a repeat PET/CT scan 4 to 6 weeks later may help identify those patients who can be safely observed without surgery to the neck. ${ }^{73}$ These patients may also continue to be observed if the clinical examination is reassuring.

\section{Long-Term Evaluation of Recurrent Disease}

Recurrences in patients with head and neck cancer tend to occur in the first 3 years after treatment, with more occurring earlier rather than later in this interval. There is little evidence to support imaging surveillance in the long-term (ie, more than 6 months after treatment) in patients who have negative imaging results, ${ }^{65,74}$ though delayed or late recurrences are more common in patients with HPV-related H\&N cancer. ${ }^{75}$ A meta-analysis including 
- H\&P exam (including a complete head and neck exam; and mirror and fiberoptic examination): ${ }^{\text {b }}$

- Year 1, every 1-3 mo

- Year 2, every 2-6 mo

- Years 3-5, every 4-8 mo

1>5 years, every $12 \mathrm{mo}$

- Imaging (See Principles of Imaging, IMG-A*)

- Thyroid-stimulating hormone (TSH) every 6-12 mo if neck irradiated.

- Dental evaluation ${ }^{c}$ for oral cavity and sites exposed to significant intraoral radiation treatment.

- Consider EBV DNA monitoring for nasopharyngeal cancer (category 2B).

- Supportive care and rehabilitation:

- Speech/hearing and swallowing evaluation ${ }^{\mathrm{d}}$ and rehabilitation as clinically indicated.

- Nutritional evaluation and rehabilitation as clinically indicated until nutritional status is stabilized. ${ }^{d}$

- Ongoing surveillance for depression (See NCCN Guidelines for Distress Management ${ }^{\dagger}$ ).

- Smoking cessation ${ }^{e}$ and alcohol counseling as clinically indicated.

- Integration of survivorship care and care plan within 1 year, complementary to ongoing involvement from a head and neck oncologist (See NCCN Guidelines for Survivorship $\left.{ }^{\dagger}\right)^{f}$

aMost recurrences are reported by the patient

bFor mucosal melanoma and paranasal sinus cancers, a physical exam eAll current smokers should be advised to quit smoking, and former smokers should be advised should include endoscopic inspection for paranasal sinus disease. to remain abstinent from smoking. For additional cessation support, refer to the Patient/

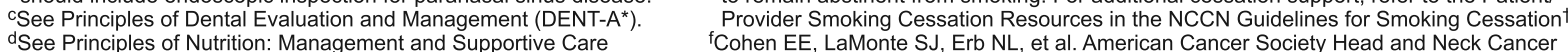
$($ NUTR-A*)

*Available online, in these guidelines, at NCCN.org. †To view the most recent version of these guidelines, visit NCCN.org.

Version $2.2020,06 / 09 / 20 \odot$ National Comprehensive Cancer Network, Inc. 2020. All rights reserved.
The NCCN Guidelines ${ }^{\circledR}$ and this illustration may not be reproduced in any form without the express written permission of NCCN.

7 studies with 577 scans showed that FDG PET/CT showed high sensitivity (92\%) and specificity (91\%) values for detection of $\mathrm{H} \& \mathrm{~N}$ cancer recurrence 12 months after treatment. ${ }^{76}$ However, a retrospective study including 1,114 patients with $H \& N$ cancer showed that PET/CT scans conducted at 12 and 24 months after treatment completion become less equivocal with time. ${ }^{74}$ Further, among patients with negative 3-month scans, no significant differences in subsequent survival outcomes were seen in patients whose recurrences were detected through PET/CT versus those with clinically detected recurrences. Despite this, the danger of distant metastasis from occult or asymptomatic disease should be acknowledged. A single-institution retrospective study including 123 patients with treated H\&N cancer showed that asymptomatic lesions were detected in $20 \%$ of patients, with half of these being thoracic lesions. ${ }^{77}$

$\mathrm{H} \& \mathrm{~N}$ cancer treatment can result in fibrosis and altered anatomy, which frequently leads to challenges in physical examination that may be assisted by follow-up imaging. Ultimately, the plan for long-term surveillance should take into account tumor site, stage, prognostic factors, presence of symptoms, and changes based on clinical exam. Neck ultrasound, which is widely available, inexpensive, safe, and accurate, may be used to evaluate suspected nodal disease. ${ }^{51}$ For areas difficult to visualize by clinical examination (ie, due to anatomy or areas obscured by treatment change), routine annual imaging using the pretreatment imaging modality (usually CT or MRI) may be indicated. The impact of annual screening for lung metastasis or synchronous lung cancer in patients with a heavy smoking history is an area in need of investigation. Annual chest CT should be considered for these patients. Many clinicians obtain chest X-ray for lung screening, but this is not supported by strong evidence due to limited sensitivity ${ }^{78,79}$ (see NCCN Guidelines for Lung Cancer Screening, available at NCCN.org).

\section{Principles of Nutrition and Supportive Care}

The "Principles of Nutrition" section in the guidelines for online (available at NCCN.org) outlines nutritional management and supportive care for patients with H\&N cancers who are prone to weight loss, which can often be severe, as a result of treatment-related toxicity, disease, and health behaviors such as poor nutritional habits. ${ }^{22,80,81}$ Patients with $\mathrm{H} \& \mathrm{~N}$ cancers are also at risk for dehydration. 


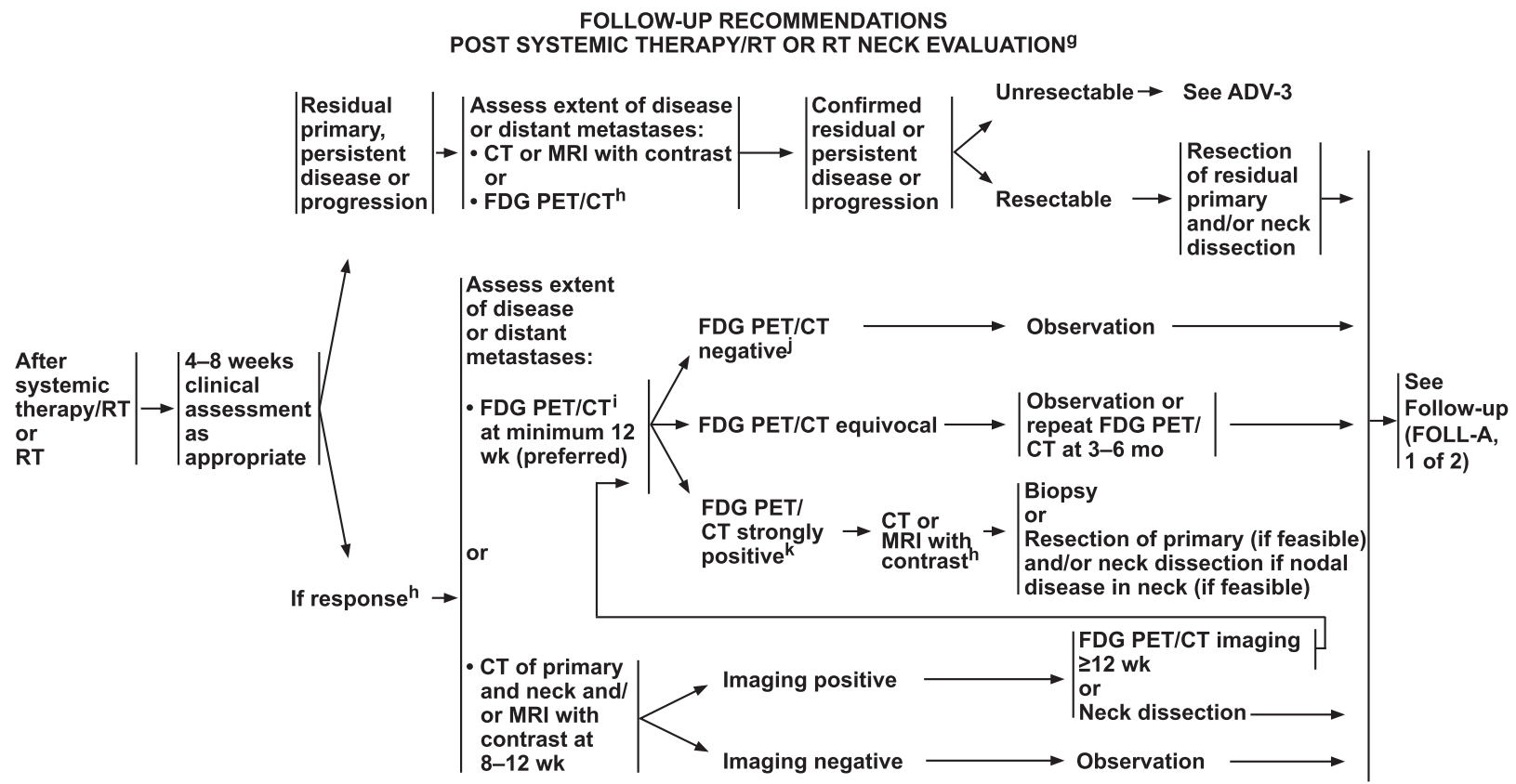

gAdapted with permission from Kutler DI, Patel SG, Shah JP. The role of neck dissection following definitive chemoradiation. Oncology 2004;18:993-998

h See Principles of Imaging (IMG-A*).

IIf an FDG PET/CT is performed and negative for suspicion of persistent cancer, further cross-sectional imaging is optional.

jPET negative $=$ No or low-grade uptake, felt not suspicious for disease.

$\mathrm{RPET}$ positive $=\mathrm{PET}$ suspicious for disease

The multidisciplinary expertise of a registered dietitian and a speech-language/swallowing therapist should be used throughout the continuum of care.

Patients who have had significant weight loss $(5 \%$ body weight loss over 1 month, or $10 \%$ body weight loss over 6 months) need nutritional evaluation and close monitoring of their weight to prevent further weight loss. ${ }^{82,83}$ In addition, all patients should receive nutritional evaluation before and after treatment to assess the need for interventions (eg, enteral support via feeding tubes) ${ }^{84-86}$ Patients are also at risk for problems with speech. Treatment and/or the progression of their disease may cause deterioration in their ability to speak and/or swallow. ${ }^{87-90}$ Evaluation by a speech-language/swallowing therapist is needed before and after treatment to help mitigate potential problems. ${ }^{91-93}$ Patients are also at risk for dental problems (see "Principles of Dental Evaluation and Management" in these guidelines at NCCN.org and page 886). ${ }^{22}$ Long-term swallowing and dental dysfunction are particular risks that are worsened by multimodality therapy and require long-term specialized attention.

Oral mucositis, or tissue damage, is common in patients treated with RT for H\&N cancers, ${ }^{94-99}$ though use of advanced RT techniques (eg, intensity-modulated RT [IMRT]) may decrease the incidence and duration of this damage ${ }^{94,100}$ Oral mucositis causes pain in the mouth and when swallowing, which may affect the ability to eat and drink..$^{94,96,98,99}$ Oral mucositis is also associated with breaks and/or delays in treatment, as well as hospitalization..$^{95,97,99}$ Oral mucositis is worse in patients receiving concurrent systemic therapy/RT. ${ }^{99}$ The Multinational Association of Supportive Care in Cancer and the International Society of Oral Oncology have published clinical practice guidelines for treatment of oral mucositis, though there are few high-quality studies in this area. ${ }^{101}$ In the randomized phase III Alliance A221304 trial, patients with $H \& N$ cancer who were treated with RT $(\mathrm{n}=275)$ were randomized to receive a diphenhydraminelidocaine-antacid mouthwash, doxepin mouthwash, or a placebo. ${ }^{102}$ The reduction in mucositis pain during the first 4 hours of treatment was significantly greater in the patients who received the diphenhydramine-lidocaineantacid mouthwash $(P=.004)$ or the doxepin mouthwash $(P=.02)$, compared with the placebo. Two small retrospective studies including patients with $\mathrm{H} \& \mathrm{~N}$ cancer treated with RT or systemic therapy/RT showed that 


\section{PRINCIPLES OF SYSTEMIC THERAPY}

\begin{tabular}{|c|c|c|}
\hline Cavity, Oropharynx, Hypophary & upraglottic Larynx, E & Sinus, Maxillary Sinus, Occult Primary) \\
\hline $\begin{array}{l}\text { - The choice of systemic therapy shoul } \\
\text { - The preferred chemoradiotherapy approac } \\
\text { - Cisplatin-based induction chemotherapy } \\
\text { improvement in overall survival with the it } \\
\text { chemoRT (cisplatin preferred, category 1) } \\
\text { - Cisplatin-based induction chemotherapy f } \\
\text { - After induction chemotherapy, multiple oo } \\
\text { patients with complete response after ind }\end{array}$ & $\begin{array}{l}\text { be individualized based on patient che } \\
\text { h for fit patients with locally advanced dise } \\
\text { an be used, followed by radiation-based lo } \\
\text { corporation of induction chemotherapy co } \\
\text { has not been established in randomized st } \\
\text { ollowed by high-dose, every-3-week cisplat } \\
\text { tions can be used for the radiation-based p } \\
\text { uction chemotherapy. }\end{array}$ & $\begin{array}{l}\text { aracteristics (eg, PS, goals of therapy). } \\
\text { ase remains concurrent cisplatin and radiotherapy. } \\
\text { coregional treatment (ie, sequential chemoRT). However, an } \\
\text { mpared to proceeding directly to state-of-the-art concurrent } \\
\text { udies. } \\
\text { in chemoradiotherapy is associated with toxicity concerns }{ }^{1,2} \\
\text { ortion of therapy, including radiotherapy alone, particularly for }\end{array}$ \\
\hline Primary Systemic Therapy + Concurren & tRT & \\
\hline Preferred Regimens & Other Recommended Regimens & Useful in Certain Circumstances \\
\hline $\begin{array}{l}\text { - High-dose cisplatin } \\
\text { - Carboplatin/infusional (category 1) } \\
\text {-FU (category 1) }\end{array}$ & $\begin{array}{l}\text { - 5-FU/hydroxyurea }{ }^{7} \text { (category 2B) } \\
\text { - Carboplatin/paclitaxel }{ }^{8} \text { (category 2B) } \\
\text { - Cetuximab }{ }^{9} \text { (category 2B) } \\
\text { - Cisplatin/infusional 5-FU }{ }^{10} \text { (category 2B) } \\
\text { - Cisplatin/paclitaxel } \text { (category 2B) }^{-} \text {- Weekly cisplatin } 40 \mathrm{mg}^{2} \mathrm{~m}^{2} \text { (category 2B) }{ }^{11,12}\end{array}$ & $\begin{array}{l}\text { - Select ethmoid/maxillary sinus cancers (small cell, SNEC, high-grade } \\
\text { olfactory esthesioneuroblastoma, SNUC with neuroendocrine features): } \\
\text { Carboplatin/etoposide } \pm \text { concurrent } \mathrm{RT}^{13} \\
\text { Cisplatin/etoposide } \pm \text { concurrent } \mathrm{RT}^{13,14} \\
\text { Cyclophosphamide/doxorubicin/vincristine (followed by RT-based } \\
\text { treatment) (category } 2 \mathrm{~B} \text { ) }\end{array}$ \\
\hline temic Therapy/R & & \\
\hline $\begin{array}{l}\text { Preferred Regimens } \\
\cdot \text { Cisplatin }^{15-20} \text { (category } 1 \text { for high-risk }{ }^{a} \\
\text { non-oropharyngeal cancers) }\end{array}$ & $\begin{array}{l}\text { Other Recommended Regimens } \\
\text { - None }\end{array}$ & $\begin{array}{l}\underline{\text { Useful in Certain Circumstances }} \\
\cdot \text { Docetaxel/cetuximab }{ }^{21} \text { (category } 2 \mathrm{~B} \text { ) } \\
\text { (if cisplatin ineligible and positive margins and/or extranodal extension) }\end{array}$ \\
\hline Induction ${ }^{\mathrm{b}} /$ Sequential Systemic T & & \\
\hline $\begin{array}{l}\text { Preferred Regimens } \\
\text { - Docetaxel/cisplatin/5-FU22-25 } \\
\text { (category } 1 \text { if induction is chosen) }\end{array}$ & $\begin{array}{l}\text { Other Recommended Regimens } \\
\text { - Paclitaxel/cisplatin/infusional 5-FU' }\end{array}$ & \\
\hline Systemic Therapy/RT following inductic & in therapy, or combination & for recurrent/persistent disease ${ }^{2,27,28}$ \\
\hline $\begin{array}{l}\text { Preferred Regimens } \\
\text { - Weekly carboplatin }+ \text { concurrent RT } \\
\text { - Weekly cisplatin (category } 2 \mathrm{~B} \text { ) + concurrent RT }\end{array}$ & $\begin{array}{l}\text { Other Recommended Regimens } \\
\text { - Weekly cetuximab + concurrent RT }\end{array}$ & \\
\hline $\begin{array}{l}\text { dverse features: extranodal extension and/ } \\
\text { he categories of evidence and consensus } f\end{array}$ & $\begin{array}{l}\text { itive margins or close } \\
\text { iction therapy vary } d\end{array}$ & $\begin{array}{l}\text { Contin } \\
\text { ease-specific site in the Head and Neck Table of Contents }{ }^{*} \text { ) }\end{array}$ \\
\hline *Available online, in these guidelines, at NCCN.org. & & See Refere \\
\hline & & 10 \\
\hline
\end{tabular}

treatment with gabapentin for pain from oral mucositis is associated with a reduced need for narcotic pain medication and high doses of opioids. ${ }^{98,103}$ A single institution study demonstrated that very high-dose prophylactic gabapentin $(2,700 \mathrm{mg}$ daily) also reduced the number of patients requiring narcotics. ${ }^{104}$ The toxicity of large dosages should not be underestimated and was not adequately explored in this single institution study. Larger scale studies are awaited to fully assess the generalizability and toxicity of this dosing schedule. The panel recommends consideration of doxepin, diphenhydramine-lidocaineantacid mouthwash, or gabapentin for pain related to oral mucositis, as clinically indicated and as tolerated.

The NCCN H\&N Panel Members agree that reactive feeding tube placement is appropriate in selected patients with $H \& N$ cancers. ${ }^{81,85}$ No consensus was reached about whether prophylactic tube placement is appropriate. Advantages of prophylactic tube placement include reductions in hospitalizations and treatmentrelated weight loss, and improved quality of life. ${ }^{105}$ However, this practice is also associated with disadvantages, such as longer dependence on feeding tubes and worse long-term functional outcomes, compared with a reactive approach. ${ }^{105}$ The NCCN Guidelines provide recommendations for prophylactic tube placement, which should be strongly considered in high-risk patients (eg, those with severe pretreatment weight loss, ongoing dehydration or dysphagia, significant comorbidities, severe aspiration, anticipated swallowing issues). ${ }^{81,83}$ In patients with adequate swallowing function, care must be given with the help of speech and language pathologists to ensure that patients continue to swallow to prevent severe fibrosis and permanent feeding tube dependence (see "Principles of Nutrition: Management and Supportive Care" in these guidelines at NCCN.org). With swallowing therapy, adequate pain control, and access to intravenous fluids, feeding tubes can be avoided in most patients. The NCCN Guidelines for $H \& N$ Cancers do not recommend prophylactic tube placement in lower-risk patients (ie, those without significant pretreatment weight loss, significant aspiration, or severe dysphagia), although these patients' weights should be carefully monitored during and after treatment. 
Non-Nasopharyngeal Cancer: Recurrent, Unresectable, or Metastatic (with no surgery or RT option)

- The choice of systemic therapy should be individualized based on patient characteristics (eg, PS, goals of therapy).

\begin{tabular}{|c|c|c|c|}
\hline \multicolumn{4}{|l|}{ Lip, Oral Cavity, Oropharynx, Hypopharynx, } \\
\hline Preferred Regimens (First-Line) & \multicolumn{2}{|c|}{ Other Recommended Regimens (First-Line) } & Useful in Certain Circumstances (First- and \\
\hline - Cetuximab/platinum (cisplatin or & \multirow{4}{*}{$\begin{array}{l}\text { Combination Therapy } \\
\text { - Cisplatin/cetuximab } \\
\text { - Cisplatin or carboplatin/ } \\
\text { docetaxel }{ }^{37} \text { or paclitaxel } \\
\text { - Cisplatin/5-FU } \\
\text { - } \text { Cisplatin or carboplatin// }^{38} \\
\text { docetaxel/cetuximab } 40 \\
\text { - Cisplatin or carboplatin/ } \\
\text { paclitaxel/cetuximab }^{41}\end{array}$} & \multirow{4}{*}{$\begin{array}{l}\text { Single Agents } \\
\text { - Cisplatin } 36,42 \\
\text { - } \text { Carboplatin } 43 \\
\text { - Paclitaxel } \\
\text { - Docetaxel } \\
\text { - }{ }^{45,46} \\
\text { - } \text { Methotrexate }^{42} \\
\text { - Cetuximab } \\
\text { - }{ }^{48} \\
\text { - } \text { Capecitabine }^{49}\end{array}$} & \multirow{4}{*}{$\begin{array}{l}\text { Subsequent-Line) } \\
\text { - For select ethmoid/maxillary sinus cancers (small cell, } \\
\text { SNEC, high-grade olfactory esthesioneuroblastoma, } \\
\text { SNUC with neuroendocrine features): } \\
\text { Cisplatin/etoposide or carboplatin/etoposide }{ }^{14} \\
\text { Cyclophosphamide/doxorubicin/ } \\
\text { vincristine (category 2B) }\end{array}$} \\
\hline carboplatin)/5-FU ${ }^{\mathrm{c}, 29}$ (category 1 ) & & & \\
\hline $\begin{array}{l}\text { - Immunotherapy } \\
\text { Pembrolizumab/platinum (cisplatin or } \\
\text { carboplatin)/5-FU }{ }^{c, 30} \text { (category } 1 \text { ) } \\
\text { - Pembrolizumab (for tumors that express PD-L1 } \\
\text { with CPS } \geq 1)^{30,31} \text { (category } 1 \text { if } C P S \geq 20 \text { ) }\end{array}$ & & & \\
\hline Preferred Regimens (Subsequent-Line) & & & \\
\hline - Immunotherapy (if not previously used) & \multicolumn{3}{|c|}{ Other Recommended Regimens (Subsequent-Line) } \\
\hline $\begin{array}{l}\text { Nivolumab }{ }^{32} \text { if disease progression on or after } \\
\text { platinum therapy (category } 1 \text { ) } \\
\text { Pembrolizumab } 33-35 \text { if disease progression on } \\
\text { or after platinum therapy (category } 1 \text { ) }\end{array}$ & \multicolumn{3}{|c|}{$\begin{array}{l}\text { - Combination Therapy or Single Agents } \\
\text { See preferred and other recommended first-line } \\
\text { therapy options above } \\
\text { - Targeted Therapy } \\
\text { - Afatinib } 50 \text { if disease progression on or after } \\
\text { platinum therapy (category } 2 \mathrm{~B} \text { ) }\end{array}$} \\
\hline
\end{tabular}

Salivary Gland Tumors

Preferred Regimens

- None
Other Recommended Regimens

- Chemotherapy (eg, cisplatin/vinorelbine, or cisplatin/ doxorubicin/cyclophosphamide [category 2B])

\begin{abstract}
${ }^{c}$ Data suggest an overall survival advantage for patients treated with pembrolizumab/platinum/5-FU when compared to cetuximab/platinum/5-FU for first-line treatment of recurrent/metastatic head and neck squamous cell carcinoma. (Rischin D, Harrington KJ, Greil R, et al. Protocol-specified final analysis of the phase 3 KEYNOTE-048 trial of pembrolizumab (pembro) as first-line therapy for recurrent/metastatic head and neck squamous cell carcinoma (R/M HNSCC). J Clin Oncol 2019:37(15_suppl): Abstract 6000.)
\end{abstract}

Version 2.2020, 06/09/20 ๑ National Comprehensive Cancer Network, Inc. 2020. All rights reserved.
The NCCN Guidelines ${ }^{\circ}$ and this illustration may not be reproduced in any form without the express written permission of NCCN.
Useful in Certain Circumstances

- Androgen receptor therapy for AR+ tumors

- Leuprolide ${ }^{51}$

Leuprolide 51,52

- NTRK therapy for NTRK gene fusion-positive tumors

- Larotrectinib 53,54

- Entrectinib ${ }^{55,56}$

- HER2 targeted therapy for HER2+ tumors (category 2B)

- Trastuzumab 57

- Lenvatinib (category 2B) for adenoid cystic carcinoma ${ }^{58}$

Continued

See References

SYST-A

2 OF 6

\section{Principles of Dental Evaluation and Management}

Patients with H\&N cancers are at risk for oral and dental complications after surgery or RT because of treatmentinduced xerostomia and salivary gland dysfunction, which are associated with increased dental caries..$^{90,94,106-108}$ In addition, RT to the salivary and oral soft tissues is also associated with bone demineralization and trismus of the masticatory muscles. Using IMRT and limiting the RT dose to the salivary glands and oral cavity have been shown to decrease xerostomia and damage to the teeth. ${ }^{106,107,109-115}$ Dental/oral evaluation and management can help decrease dental caries and associated problems such as dentoalveolar infection and osteoradionecrosis. ${ }^{94,109,115-124}$

The recommended dental/oral evaluations before, during, and after RT are described in detail in the algorithm and summarized here. A dental/oral treatment plan needs to be implemented before RT and should include the following: (1) eliminating potential sources of infection; (2) if performing dental extractions, allow adequate time for healing before RT; (3) treating active dental caries and periodontal disease; (4) treating oral candidiasis; and (5) educating patients about preventive strategies. ${ }^{125}$ Some of the general strategies to decrease oral and dental complications include (1) decrease dry mouth (eg, by using salivary substitutes and stimulation) ${ }^{126-130}$; (2) reduce risk of dental caries (eg, by using topical fluoride) ${ }^{116,131-134}$; (3) decrease dentoalveolar infection (eg, with frequent evaluations to detect and treat disease promptly); (4) prevent and address osteoradionecrosis ${ }^{135}$; (5) decrease trismus of the masticatory muscles (eg, by using custom mouth-opening devices to maintain range of motion) ${ }^{136-138}$; and (6) have patient undergo evaluations during and after treatment to help minimize complications. ${ }^{126,127,139,140}$ Major dental work such as extractions can be problematic for an irradiated mandible. Therefore, any planned procedures should be performed by dentists wellacquainted with this treatment setting and potential related morbidities, and in consultation with the treating radiation oncologist.

During and after treatment, the goals of dental/oral management include (1) addressing xerostomia; (2) preventing trismus; and (3) detecting and treating oral candidiasis. ${ }^{125}$ Additional goals after treatment include (1) preventing and treating dental caries; (2) surveying 
the mouth for early signs of postradiation osteonecrosis; and (3) preventing oral candidiasis. ${ }^{125}$

\section{Very Advanced H\&N Cancers}

Very advanced H\&N cancers include (1) newly diagnosed locally advanced T4b (M0); (2) newly diagnosed unresectable regional nodal disease, typically N3; (3) metastatic disease at initial presentation (M1); or (4) recurrent or persistent disease. The treatment goal is usually cure for patients with newly diagnosed locoregional but unresectable disease. For recurrent disease, the goal is cure if surgery or radiation remains feasible, or palliation if the patient has received previous RT and the disease is unresectable. For patients with widely metastatic disease, the goal is palliation or prolongation of life.

\section{Treatment}

The treatment of patients with unresectable locoregional, persistent, recurrent, or metastatic $\mathrm{H} \& \mathrm{~N}$ cancers is dictated by the patient's performance status (PS) and intent of treatment (ie, palliative vs curative). Patients with good PS may tolerate a wide range of treatment options, whereas patients with reduced PS cannot.

\section{Newly Diagnosed Locoregionally Advanced Disease} Many randomized trials ${ }^{14-150}$ and meta-analyses ${ }^{151-155}$ show significantly improved overall survival (OS), diseasefree survival, and locoregional control when a systemic therapy and radiation regimen (concomitant or, less commonly, sequential) is compared with RT alone for locoregionally advanced disease. Limited data are available comparing the efficacy of different chemoradiotherapy regimens.

High-dose cisplatin plus RT is effective and typically uses conventional fractionation at $2.0 \mathrm{~Gy}$ per fraction to 70 Gy in 7 weeks with concurrent single-agent cisplatin given every 3 weeks at $100 \mathrm{mg} / \mathrm{m}^{2} \cdot{ }^{141,156}$ Because of concerns about toxicity, a weekly lower dose cisplatin regimen $\left(40 \mathrm{mg} / \mathrm{m}^{2} / \mathrm{wk}\right)$ may be substituted, or other better tolerated regimens, although the categories of evidence for these regimens are lower than for high-dose cisplatin. In the absence of clearly definitive prospective comparison trials, it is unclear whether weekly cisplatin is either less toxic or equally efficacious as high-dose cisplatin.

Epidermal growth factor receptor (EGFR) overexpression is common in squamous cell $H \& N$ cancers and is associated with poor survival outcomes. ${ }^{157,158}$ These findings have led to the development of EGFR inhibitors, such as the EGFR monoclonal antibody cetuximab. Bonner et al ${ }^{159}$ randomly assigned 424 patients with locally advanced stage III to IV squamous cell carcinomas of the hypopharynx, oropharynx, and larynx to receive definitive RT with or without cetuximab.
Locoregional control and median OS (49 vs 29.3 months; $P=.03$ ) were significantly improved in patients treated with RT and cetuximab compared with RT alone. Fiveyear OS in these patients was $45.6 \%$ in patients treated with RT and cetuximab and $36.4 \%$ in patients who received RT alone (hazard ratio $[\mathrm{HR}], 0.73 ; 95 \% \mathrm{CI}$, $0.56-0.95 ; P=.018) .{ }^{160}$

The addition of cetuximab to cisplatin and RT was hypothesized to improve efficacy outcomes compared with cisplatin and RT. However, the randomized phase III RTOG 0522 trial showed that the addition of cetuximab to cisplatin and RT did not significantly improve OS in patients with stage III or IV H\&N cancer and, importantly, was more toxic. ${ }^{161}$ In the phase III GORTEC 2007-01 trial, cetuximab combined with carboplatin/5-FU and RT was compared with cetuximab and RT. ${ }^{162}$ Threeyear progression-free survival (PFS) $(52.3 \%$ vs $40.5 \%$, respectively; HR, $0.73 ; 95 \% \mathrm{CI}, 0.57-0.94 ; P=.015)$ and locoregional failure ( $21.6 \%$ vs $38.8 \%$, respectively; HR, 0.54 ; 95\% CI, $0.38-0.76 ; P<.001)$ rates were significantly better for the combination regimen, but OS and distant metastases rates were not statistically significant. Grade 3 or 4 mucositis ( $73 \%$ vs $61 \%$, respectively; $P=.014)$ and hospitalization for toxicity ( $42 \%$ vs $22 \%$, respectively; $P<.001$ ) were significantly more prevalent in patients who received cetuximab combined with carboplatin/5-FU and RT. Cetuximab combined with chemoradiation continues to not be routinely used in the definitive treatment setting.

Cetuximab and RT was compared with cisplatin and RT in 2 randomized phase III trials as a deintensification treatment strategy for HPV-associated locally advanced oropharyngeal cancer, but proved inferior to cisplatin in this setting in terms of OS and was also not better tolerated. ${ }^{163,164}$ In the RTOG 1016 noninferiority trial, 849 patients with locally advanced HPV-positive oropharyngeal cancer were randomized to receive accelerated IMRT with either cetuximab or cisplatin. ${ }^{163}$ After a median follow-up of 4.5 years, the cetuximab arm did not meet the criterion for noninferiority (based on 5-year OS). Five-year OS was $77.9 \%$ for the cetuximab arm and $84.6 \%$ for the cisplatin arm. PFS and risk of locoregional failure were significantly worse in the cetuximab arm compared with the cisplatin arm (HR, 1.72; 95\% CI, 1.29-2.29; $P<.001$ for PFS; HR, 2.05; 95\% CI, 1.35-3.10; $P<.001$ for locoregional failure), with 5-year PFS and locoregional failure rates being $67.3 \%$ and $17.3 \%$ for the cetuximab arm, and $78.4 \%$ and $9.9 \%$ for the cisplatin arm, respectively. In the smaller but similarly designed randomized phase III De-ESCALaTE HPV trial, cetuximab and RT was compared with cisplatin and RT in 334 patients with locally advanced p16-positive oropharyngeal squamous cell carcinoma. ${ }^{164}$ Patients given cisplatin and RT had significantly better 2-year OS $(97.5 \%$ vs 
89.4\%, respectively; HR, 5.0; 95\% CI, 1.7-14.7; $P=.001$ ) and a lower recurrence rate $(6.0 \%$ vs $16.1 \%$, respectively; HR, 3.4; 95\% CI, 1.6-7.2; $P<.001)$ compared with patients given cetuximab and RT. These phase III trials demonstrate that cetuximab and RT is inferior to cisplatin and RT in patients with HPV-related oropharyngeal cancer. ${ }^{163,164}$

Therefore, in patients with a PS of 0 or 1 , the recommended treatment of newly diagnosed, very advanced disease is concurrent systemic therapy/RT, with a large amount of phase III data supporting high-dose cisplatin as a category 1 preferred recommendation. ${ }^{141,165}$ There is also considerable phase III data from Europe that supports the use of carboplatin/5-FU with concurrent RT. ${ }^{166}$ This treatment is also considered a category 1 preferred option. Cisplatin-based induction systemic therapy can be used, followed by radiation-based locoregional treatment (ie, sequential chemoradiation). However, an improvement in OS with the incorporation of induction chemotherapy, compared with proceeding directly to state-of-the-art concurrent systemic therapy/RT has not been established in randomized studies. ${ }^{167,168}$ Cetuximab with concurrent RT is a category $2 \mathrm{~B}$ option based on phase II and phase III data but is distinctly inferior to cisplatin with concurrent RT, as discussed previously. $160,163,164,169$ Other chemoradiation options that are also category 2B based on less panel consensus include 5-FU/hydroxyurea, cisplatin with infusional 5-FU, platinum combined with paclitaxel, and weekly cisplatin $40 \mathrm{mg} / \mathrm{m}^{2} .{ }^{170-174}$ Other options for patients with a PS of 2-3 are described in the algorithm (see "Treatment of Newly Diagnosed (M0) T4b, N0-3 or Unresectable Nodal Disease or Unfit for Surgery," page 874). Primary systemic therapy/RT regimens are listed in the "Principles of Systemic Therapy" in the algorithm (see "Principles of Systemic Therapy for NonNasopharyngeal Cancer: Primary Definitive Therapy," page 885). Radiation therapy fractionation for patients with newly diagnosed, very advanced disease is described in the "Principles of Radiation Therapy" in the NCCN Guidelines at NCCN.org.

\section{Metastatic Disease}

For patients with metastatic (M1) disease at initial presentation, palliative adjunctive measures include analgesics and other measures to control manifestations of disease spread (eg, pain, hypercalcemia, malnutrition). Locoregional treatment (eg, surgery, RT, or ablative therapies) may be used for oligometastatic disease. ${ }^{175-177}$

Single agent and combination systemic therapy are both used (see "Treatment of Metastatic Disease at Initial Presentation" and "Principles of Systemic Therapy for Non-Nasopharyngeal Cancer: Recurrent, Unresectable, or Metastatic," pages 875 and 886). ${ }^{178}$ Response rates to single-agent therapies range from $15 \%$ to $35 \% .{ }^{179-181}$ Randomized trials assessing a cisplatin-based combination regimen (cisplatin/5-FU) versus single-agent therapy with cisplatin, 5-FU, or methotrexate showed significantly higher response rates, but no difference in OS and greater toxicity for the combination regimen. ${ }^{182-186}$ Complete response is associated with longer survival and, although infrequent, has been reported more often with combination regimens. ${ }^{183} \mathrm{~A}$ phase III randomized trial (EXTREME) of 442 patients found that cetuximab plus cisplatin/5-FU or carboplatin/5-FU improved median survival compared with the standard chemotherapy doublet of platinum/5-FU (10.1 vs 7.4 months; $P=.04$ ). ${ }^{187}$ The response rate was $\mathrm{im}$ proved with the addition of cetuximab ( $36 \%$ vs $20 \%$; $P<.001)$. A randomized phase III trial found no significant difference in survival when comparing cisplatin/5-FU and cisplatin/paclitaxel. ${ }^{182}$

Trials evaluating immune checkpoint inhibitors demonstrated efficacy in patients with recurrent or metastatic HNSCC. ${ }^{188-190}$ Pembrolizumab, an anti-PD-1 antibody, was evaluated as a first-line option for recurrent or metastatic HNSCC in the KEYNOTE-048 trial $(\mathrm{n}=882) .{ }^{188}$ Patients were randomized to receive pembrolizumab, pembrolizumab with a platinum and 5-FU, or the EXTREME regimen. In the total population, an OS benefit was observed in the pembrolizumab with a platinum and 5-FU arm, compared with the EXTREME arm (median OS, 13 vs 10.7 months, respectively; HR, 0.77; 95\% CI, 0.63-0.93; $P=.003$ ). PFS, however, did not significantly differ between these 2 study arms. In patients with a PD-L1 combined positive score (CPS) of both $\geq 20$ and $\geq 1$, median OS was better in patients who received pembrolizumab monotherapy, compared with those who received the EXTREME regimen (median 14.9 vs 10.7 months, respectively; HR, 0.61; 95\% CI, 0.45-0.83; $P<.001$, for CPS $\geq 20$; median 12.3 vs 10.3 months, respectively; HR, 0.78 ; 95\% CI, 0.64-0.96; $P=.009$, for CPS $\geq 1$ ). Median duration of response was greater in patients treated with pembrolizumab monotherapy or pembrolizumab with chemotherapy, compared with patients treated with the EXTREME regimen.

Based on the results of KEYNOTE-048, ${ }^{188}$ the panel considers pembrolizumab/platinum/5-FU a preferred first-line option (category 1) for all patients with recurrent, unresectable, or metastatic disease who have no surgical or radiotherapeutic option. The panel also considers pembrolizumab monotherapy as a preferred first-line option for patients with CPS $\geq 1$ (category 1 if CPS $\geq 20$ ). Other combination regimens recommended by the panel for treatment of metastatic HNSCC include (1) cisplatin or carboplatin, plus 5-FU with cetuximab (category 1; preferred) ${ }^{187}$; (2) cisplatin or carboplatin, plus a taxane ${ }^{182,191}$; (3) cisplatin with cetuximab ${ }^{192,193}$; (4) cisplatin with $5-\mathrm{FU}^{182,183}$; or (5) cetuximab with a platinum and a taxane. ${ }^{193-196}$ Single agents recommended by the panel include cisplatin, carboplatin, 
paclitaxel, docetaxel, 5-FU, methotrexate, capecitabine, and cetuximab. ${ }^{178,181,183,184,192,197-205}$

\section{Recurrent or Persistent Disease}

Surgery is recommended for resectable recurrent or persistent locoregional disease, in the absence of distant metastatic disease; adjuvant therapy depends on the risk factors (see "Recurrent or persistent disease," page 874). Patients with resectable recurrent or persistent locoregional disease who have not previously been treated with RT may also be treated with concurrent systemic therapy/RT (high-dose cisplatin is the preferred [category 1] systemic agent). ${ }^{141}$ Combination systemic therapy followed by RT or systemic therapy/RT is a category 3 recommendation for these patients. If the recurrence is unresectable and the patient had not had prior RT, then RT with concurrent systemic therapy is recommended, depending on the PS (see "Recurrent or persistent disease," page 874). For patients with recurrent disease who are not amenable to curative-intent radiation or surgery, the treatment approach is the same as that for patients with metastatic disease. Locoregional treatment may be considered in the presence of distant metastasis with locoregional failure. RT fractionation for patients with recurrent or persistent disease is described in the "Principles of Radiation Therapy" in these guidelines online (available at NCCN.org).

\section{Disease That Has Progressed on or}

\section{After Platinum Therapy}

For failure of platinum-based therapy, options are listed in the algorithm (see "Principles of Systemic Therapy for Non-Nasopharyngeal Cancer: Recurrent, Unresectable, or Metastatic," page 886).

Nivolumab was assessed in a phase III randomized clinical trial including 361 patients with recurrent HNSCC whose disease had progressed within 6 months after platinum-based chemotherapy. ${ }^{190}$ With a median follow-up of 5.1 (range, 0-16.8) months, the OS was significantly greater in patients given nivolumab compared with patients given standard second-line singleagent systemic therapy (methotrexate, docetaxel, or cetuximab; HR, 0.70; 97.73\% CI, 0.51-0.96; $P=.01$ ). Oneyear survival was also greater for patients who received nivolumab, relative to patients who received standard therapy ( $36.0 \%$ vs $16.6 \%$, respectively), and response rate was higher ( $13.3 \%$ vs $5.8 \%$, respectively), but median PFS was not significantly different between the 2 groups (2.0 vs 2.3 months, respectively; $P=.32$ ). In prespecified exploratory analyses, the OS benefit in patients treated with nivolumab appeared to be confined to those patients with a tumor PD-L1 expression level of $1 \%$ or more $(\mathrm{n}=149$; 8.7 vs 4.6 months; HR, 0.55 ; $95 \% \mathrm{CI}, 0.36-0.83$ ). In patients with tumor PD-L1 expression level $<1 \%$ $(\mathrm{n}=111)$, no OS advantage was shown for the nivolumabtreated patients (5.7 vs 5.8 months; HR, 0.89; 95\% CI, $0.54-1.45)$. Grade 3 or 4 treatment-related adverse events occurred in $13.1 \%$ of patients who received nivolumab, compared with $35.1 \%$ of patients who received standard therapy. These results indicate that nivolumab prolongs survival in patients with recurrent or metastatic HNSCC cancer that has progressed after platinum-based chemotherapy, relative to patients who receive standard single-agent systemic therapy.

Pembrolizumab was initially studied at a dose of 10 $\mathrm{mg} / \mathrm{kg}$ given every 2 weeks in the HNSCC cohort of the KEYNOTE-012 trial, and clinical activity was identified. ${ }^{206}$ A lower, fixed-dose schedule using pembrolizumab 200 mg every 3 weeks was subsequently assessed in a phase $1 \mathrm{~b}$ expansion cohort of 132 patients with recurrent or metastatic HNSCC. ${ }^{207}$ At 6 months, the OS rate was 59\%, and the PFS was $23 \%$, with an overall response rate of $18 \%$. Observed responses appeared durable although the follow-up was limited (median 9 months). Pembrolizumab was also generally well-tolerated. ${ }^{206}$ Pooled analyses after long-term follow-up of the initial and expansion cohorts $(\mathrm{n}=192)$ showed a 1-year OS rate of $38 \%{ }^{208}$ Among the 34 patients who showed a response, $85 \%$ of the responses lasted 6 months or longer, and $71 \%$ lasted 12 months or longer.

Based on results of the phase Ib KEYNOTE-012 trial, pembrolizumab was evaluated in the phase III KEYNOTE-040 trial. ${ }^{189}$ Patients with recurrent or metastatic HNSCC $(n=495)$ were randomized to receive pembrolizumab or another systemic therapy (methotrexate, docetaxel, or cetuximab). Median OS was greater for the pembrolizumab arm compared with the standard-of-care arm (8.4 vs 6.9 months; HR, 0.80; 95\% CI, $0.65-0.98 ; P=.016$ ). When analyses were stratified by PD-L1-status, the results for OS were significantly better with pembrolizumab only for patients with tumors that have PD-L1 expression.

The nonrandomized phase II KEYNOTE-055 trial studied pembrolizumab in 171 patients with HNSCC that progressed after treatment with both a platinum and cetuximab. ${ }^{209}$ The overall response rate was $16 \%(95 \%$ CI, $11 \%-23 \%$ ), and the mean duration of response was 8 months.

Afatinib was evaluated in the phase III LUX-Head \& Neck 1 RCT. Afatinib was compared with methotrexate in patients with recurrent or metastatic $H \& N$ cancer who had progressed on or after platinum-based therapy $(n=483){ }^{210}$ Patients randomized to receive afatinib had greater PFS compared with patients randomized to receive methotrexate (2.6 vs 1.7 months; $P=.03$ ). There were no significant differences for OS. ${ }^{210}$ The PFS benefit with afatinib seemed to be most clear in the HPV-negative group. ${ }^{211} \mathrm{~A}$ randomized phase II trial comparing afatinib 
to cetuximab in patients with recurrent or metastatic $\mathrm{H} \& \mathrm{~N}$ cancer who had progressed on or after platinumbased therapy $(n=121)$ showed comparable response rates between the 2 drugs. ${ }^{212}$

The panel recommends immunotherapy (nivolumab and pembrolizumab) as category 1 preferred options for patients with recurrent or metastatic HNSCC who have progressed on or after platinum-based chemotherapy based on high-quality evidence. ${ }^{189,190}$ Despite the ambiguities of PD-L1 testing and definitions, PD-L1 expression may be associated with better outcomes from treatment with immunotherapy for recurrent or metastatic HNSCC (ie, greater likelihood of response to pembrolizumab and greater survival benefit in response to nivolumab). For all other systemic therapy options recommended by the panel, there are no clear advantages of one agent over another in the subsequent line setting, though response rates seem to be highest with taxanes. Afatinib has a PFS benefit, but not an OS benefit, over methotrexate ${ }^{210}$ and is a category $2 \mathrm{~B}$ systemic therapy option for non-nasopharyngeal persistent $\mathrm{H} \& \mathrm{~N}$ cancer or cancer that has progressed on or after platinum-containing chemotherapy.

\section{Salivary Gland Tumors}

Guidelines recommendations regarding treatment of salivary gland tumors have recently been considerably revised, notably systemic therapy recommendations. Salivary gland tumors can arise in the major salivary glands (ie, parotid, submandibular, sublingual) or in one of the minor salivary glands, which are widely spread throughout the aerodigestive tract. ${ }^{213}$ Many minor salivary gland tumors are located on the hard palate. Approximately $20 \%$ of the parotid gland tumors are malignant; the incidence of malignancy in submandibular and minor salivary gland tumors is approximately $50 \%$ and $80 \%$, respectively. These malignant tumors constitute a broad spectrum of histologic types, including mucoepidermoid, acinic, adenocarcinoma, adenoid cystic carcinoma, malignant myoepithelial tumors, and squamous cell carcinoma. The primary diagnosis of squamous cell carcinoma of the parotid gland is rare; however, the parotid gland is a frequent site of metastasis from skin cancer. ${ }^{214}$ Prognosis and tendency to metastasize vary among these histologic types. Major prognostic factors are histologic grade, tumor size, and local invasion. Staging is done using the AJCC Cancer Staging Manual (8th edition). ${ }^{14}$

\section{Treatment}

The major therapeutic approach for salivary gland tumors is adequate and appropriate surgical resection (see "Salivary Gland Tumors: Clinically Benign or T1, T2; T3, T4a; T4b," page 879). ${ }^{215-218}$ Surgical intervention requires careful planning and execution, particularly in parotid tumor surgery, because the facial nerve is in the gland. The gland should be preserved if the nerve is not directly involved by the tumor. Most parotid gland tumors are located in the superficial lobe. If the facial nerve is functioning preoperatively, the nerve can be preserved in most patients. ${ }^{219}$ The facial nerve should be killed if there is preoperative facial nerve involvement with facial palsy or if there is direct invasion of the tumor into the nerve where the tumor cannot be separated from the nerve. Malignant deep lobe parotid tumors are quite rare; however, they are generally a challenge for the surgeon because the patient may require superficial parotidectomy and identification and retraction of the facial nerve to remove the deep lobe parotid tumor.

The panel recommends highly conformal RT techniques such as IMRT, proton, or other heavy ions for definitive radiation treatment (see "Salivary Gland Tumors: Principles of Radiation Therapy," page 882). Results from a retrospective cohort study including 545 patients with salivary gland tumors treated between 1997 and 2010 showed better local control and survival outcomes with neutron therapy, relative to photon therapy. ${ }^{220}$ However, risk of late effects with neutron therapy is high and tends to increase over time, with estimates as high as $20 \%$ at 9 years. ${ }^{221,222}$ The panel no longer recommends neutron therapy as a general solution for salivary gland cancers due to the diminishing demand, concerns regarding the methodologic robustness of available randomized trial data, and closure of all but one center in the United States. The panel recognizes the potential clinical value of neutron therapy for select patients.

Most malignant deep lobe parotid tumors will require postoperative RT because of adverse features such as the limitations of surgical margins in the resection of these tumors. ${ }^{215,217,223}$ RT is also used in an adjuvant setting for tumors with other adverse features (eg, intermediate, high grade, T3-4 tumors, or positive lymph nodes) ${ }^{216,224,225}$; systemic therapy/RT (category 2B) can also be considered. ${ }^{226}$ Efficacy data for systemic therapy/RT for patients with advanced salivary gland tumors that have been resected are limited. Extensive safety data are available and may be extrapolated from the management of HNSCC, with some NCCN Member Institutions using platinumbased regimens for these patients. With regard to unresectable salivary gland tumors, the NCCN H\&N Panel had less consensus about chemoradiation (which is reflected in the category $2 \mathrm{~B}$ recommendations), because there are few published trials. Clinical trials are ongoing in this area (eg, ClinicalTrials.gov identifiers: NCT01220583, NCT02776163).

Systemic therapy may be used for palliation in advanced disease (see algorithm pages "Salivary Gland Tumors: Treatment for Recurrence," page 881 and "Principles of Systemic Therapy: Salivary Gland Tumors," page 886). Targeted therapy is increasingly becoming an 
option for patients with distantly metastatic salivary gland tumors. A significant number of advanced salivary gland tumors with distant metastases are androgen receptor-positive. ${ }^{227-231}$ Therefore, the panel recommends that patients with tumors that are androgen receptorpositive receive androgen receptor therapy (eg, leuprolide, bicalutamide). ${ }^{231-234}$ Two phase I-II studies including patients with advanced NTRK gene fusionpositive cancer (with $22 \%-38 \%$ being salivary gland tumors) showed promising objective response rates of $75 \%-100 \%$ with the tyrosine receptor kinase (TRK) inhibitor larotrectinib. ${ }^{235,236} \mathrm{~A}$ pooled analysis from a phase II trial and 2 phase I trials including 54 patients with NTRK gene fusion-positive cancer ( $13 \%$ being mammary analog secretory carcinoma of the salivary gland) showed an objective response rate of $57.4 \%$ for entrectinib, another TRK inhibitor. ${ }^{237}$ The FDA recently approved larotrectinib and entrectinib for treatment of patients with NTRK gene fusion-positive tumors, and the panel also recommends NTRK therapy options such as larotrectinib and entrectinib for patients with recurrent NTRK gene fusion-positive salivary gland tumors and distant metastases.

Finally, HER2 positivity has also been found in some advanced salivary gland tumors. ${ }^{229,231,238}$ It is recommended that these patients receive a HER2-targeted treatment option such as trastuzumab, ${ }^{231,239,240}$ but this is a category $2 \mathrm{~B}$ recommendation based on less consensus among the panel. Small series demonstrate that adotrastuzumab emtansine may be active in patients with previously treated metastatic HER2-positive salivary gland cancers. ${ }^{241,242}$ AR and HER2 status should be checked in patients with distant metastases. NTRK status should be evaluated in mammary analog secretory carcinoma of the salivary gland. ${ }^{243}$ Various combinations of chemotherapy agents (eg, cisplatin/cyclophosphamide/doxorubicin and cisplatin/vinorelbine) have been shown in small series to be active for some salivary gland malignant histologies, with overall response rates ranging from $27 \%$ to $60 \%,{ }^{244-246}$ and chemotherapy regimens such as these are acknowledged by the NCCN Guidelines Panel as treatment options for patients with advanced disease (category 2B). A phase II trial including 32 patients with recurrent or metastatic adenoid cystic carcinoma showed a disease control rate of $88 \%$ (partial response of $15.6 \%$, stable disease in $75 \%$ ) for lenvatinib. ${ }^{247}$ Based on these results and lack of other evidence-based options for recurrent or metastatic adenoid cystic carcinoma, lenvatinib is a category 2B option. Use of other tyrosine kinase inhibitors such as axitinib, ${ }^{248}$ sorafenib, $^{249}$ sunitinib, ${ }^{250}$ and dovitinib ${ }^{251}$ have been evaluated in phase II trials for salivary gland tumors, but larger trials are needed in this area.

\section{Summary}

Much progress has been made in understanding the epidemiology, pathogenesis, and management of $\mathrm{H} \& \mathrm{~N}$ cancers. Treatment planning for $\mathrm{H} \& \mathrm{~N}$ cancers involves a multidisciplinary team of healthcare professionals with expertise in $\mathrm{H} \& \mathrm{~N}$ surgery, radiation oncology, medical oncology, plastic and reconstructive surgery, dentistry, speech and swallowing therapy, nutrition, pathology, and diagnostic/interventional radiology, among others. Care should be taken in selection of appropriate imaging studies for patients with H\&N cancers. Dental management for prevention and treatment of RT effects should be provided, as well as adequate nutritional support to prevent severe weight loss. Recent phase III RCTs support the use of immunotherapy for patients with recurrent, unresectable, or metastatic $\mathrm{H} \& \mathrm{~N}$ cancer. Immunotherapy options for patients with recurrent or metastatic HNSCC who have progressed on or after platinum-based chemotherapy include nivolumab and pembrolizumab. Pembrolizumab is also a first-line option when administered in combination with platinum/5-FU or as a monotherapy in patients with CPS $\geq 1$ (category 1 if CPS $\geq 20$ ). The panel has recently expanded the list of systemic therapy options for patients with salivary gland tumors (eg, larotrectinib and entrectinib for patients with recurrent NTRK gene fusion-positive salivary gland tumors and distant metastases).

\section{References}

1. Treatment of head and neck cancer. in.DeVita VT, Jr., Lawrence TS and Rosenberg SA, eds. DeVita, Hellman, and Rosenberg's Cancer: Principles and Practice of Oncology. Philadelphia, Pennsylvania: Lippincott Williams \& Wilkins; 2011.

2. DeVita V, Jr., Lawrence T, Rosenberg S. DeVita, Hellman, and Rosenberg's Cancer: Principles \& Practice of Oncology, 9th Ed. Philadelphia, Pennsylvania: Lippincott Williams \& Wilkins; 2011.

3. Siegel RL, Miller KD, Jemal A. Cancer statistics, 2020. CA Cancer J Clin 2020;70:7-30.

4. Siegel RL, Miller KD, Jemal A. Cancer statistics, 2019. CA Cancer J Clin 2019;69:7-34.

5. Chaturvedi AK, Engels EA, Pfeiffer RM, et al. Human papillomavirus and rising oropharyngeal cancer incidence in the United States. J Clin Oncol 2011;29:4294-4301.

6. Gillison ML, Broutian T, Pickard RK, et al. Prevalence of oral HPV infection in the United States, 2009-2010. JAMA 2012;307:693-703.

7. Chaturvedi AK, Engels EA, Anderson WF, et al. Incidence trends for human papillomavirus-related and -unrelated oral squamous cell carcinomas in the United States. J Clin Oncol 2008;26:612-619.

8. Näsman A, Attner $\mathrm{P}$, Hammarstedt $L$, et al. Incidence of human papillomavirus (HPV) positive tonsillar carcinoma in Stockholm, Sweden: an epidemic of viral-induced carcinoma? Int J Cancer 2009;125:362-366.

9. Mehanna H, Beech T, Nicholson T, et al. Prevalence of human papillomavirus in oropharyngeal and nonoropharyngeal head and neck cancer--systematic review and meta-analysis of trends by time and region. Head Neck 2013;35:747-755

10. Chua MLK, Wee JTS, Hui EP, et al. Nasopharyngeal carcinoma. Lancet 2016;387:1012-1024. 
11. Jha HC, Pei Y, Robertson ES. Epstein-Barr virus: diseases linked to infection and transformation [published online October 25, 2016]. Front Microbiol, doi:10.3389/finicb.2016.01602

12. Lo KW, To KF, Huang DP. Focus on nasopharyngeal carcinoma. Cancer Cell 2004;5:423-428.

13. Ou SH, Zell JA, Ziogas A, et al. Epidemiology of nasopharyngeal carcinoma in the United States: improved survival of Chinese patients within the keratinizing squamous cell carcinoma histology. Ann Oncol 2007;18:29-35.

14. Amin M, Edge S, Greene F, et al. AJCC Cancer Staging Manual, 8th Ed. New York: Springer; 2017

15. Wuthrick EJ, Zhang Q, Machtay M, et al. Institutional clinical trial accrual volume and survival of patients with head and neck cancer. J Clin Oncol 2015;33:156-164.

16. David JM, Ho AS, Luu M, et al. Treatment at high-volume facilities and academic centers is independently associated with improved survival in patients with locally advanced head and neck cancer. Cancer 2017;123: 3933-3942.

17. Gourin CG, Stewart CM, Frick KD, et al. Association of hospital volume with laryngectomy outcomes in patients with larynx cancer. JAMA Otolaryngol Head Neck Surg 2019;145:62-70.

18. Nocon CC, Aimani GS, Bhayani MK. Association of facility volume with positive margin rate in the surgical treatment of head and neck cancer. JAMA Otolaryngol Head Neck Surg 2018;144:1090-1097.

19. Lee NCJ, Kelly JR, An Y, et al. Radiation therapy treatment facility and overall survival in the adjuvant setting for locally advanced head and neck squamous cell carcinoma. Cancer 2019;125:2018-2026.

20. Cohen EE, LaMonte SJ, Erb NL, et al. American Cancer Society Head and Neck Cancer Survivorship Care Guideline. CA Cancer J Clin 2016;66: 203-239.

21. Jabbour J, Milross $C$, Sundaresan $P$, et al. Education and support needs in patients with head and neck cancer: A multi-institutional survey. Cancer 2017;123:1949-1957.

22. Chaukar DA, Walvekar RR, Das AK, et al. Quality of life in head and neck cancer survivors: a cross-sectional survey. Am J Otolaryngol 2009;30: 176-180.

23. So WK, Chan RJ, Chan DN, et al. Quality-of-life among head and neck cancer survivors at one year after treatment--a systematic review. Eur J Cancer 2012;48:2391-2408

24. Smith BG, Hutcheson KA, Little LG, et al. Lymphedema outcomes in patients with head and neck cancer. Otolaryngol Head Neck Surg 2015; 152:284-291.

25. Colasanto JM, Prasad P, Nash MA, et al. Nutritional support of patients undergoing radiation therapy for head and neck cancer. Oncology (Williston Park) 2005;19:371-379., discussion 380-382., 387.

26. Lin BM, Starmer HM, Gourin CG. The relationship between depressive symptoms, quality of life, and swallowing function in head and neck cancer patients 1 year after definitive therapy. Laryngoscope 2012;122: 1518-1525.

27. Krebber AM, Leemans $C R$, de Bree $R$, et al. Stepped care targeting psychological distress in head and neck and lung cancer patients: a randomized clinical trial. BMC Cancer 2012;12:173.

28. Verdonck-de Leeuw IM, de Bree R, Keizer AL, et al. Computerized prospective screening for high levels of emotional distress in head and neck cancer patients and referral rate to psychosocial care. Oral Oncol 2009;45:e129-e133.

29. Andersen BL, DeRubeis RJ, Berman BS, et al. Screening, assessment, and care of anxiety and depressive symptoms in adults with cancer: an American Society of Clinical Oncology guideline adaptation. J Clin Oncol 2014;32:1605-1619.

30. Siegel RL, Miller KD, Jemal A. Cancer statistics, 2015. CA Cancer J Clin 2015;65:5-29.

31. Schnoll RA, Zhang B, Rue $M$, et al. Brief physician-initiated quit-smoking strategies for clinical oncology settings: a trial coordinated by the Eastern Cooperative Oncology Group. J Clin Oncol 2003;21:355-365.

32. Gritz ER, Carr CR, Rapkin D, et al. Predictors of long-term smoking cessation in head and neck cancer patients. Cancer Epidemiol Biomarkers Prev 1993;2:261-270.

33. Feinstein AR. The pre-therapeutic classification of co-morbidity in chronic disease. J Chronic Dis 1970;23:455-468.

34. Piccirillo JF. Importance of comorbidity in head and neck cancer. Laryngoscope 2000;110:593-602.

35. Piccirillo JF, Lacy PD, Basu A, et al. Development of a new head and neck cancer-specific comorbidity index. Arch Otolaryngol Head Neck Surg 2002;128:1172-1179.
36. Chen AY, Matson LK, Roberts D, et al. The significance of comorbidity in advanced laryngeal cancer. Head Neck 2001;23:566-572.

37. Hall SF, Rochon PA, Streiner DL, et al. Measuring comorbidity in patients with head and neck cancer. Laryngoscope 2002;112:1988-1996.

38. Rose BS, Jeong JH, Nath SK, et al. Population-based study of competing mortality in head and neck cancer. J Clin Oncol 2011;29: 3503-3509.

39. de Graeff A, de Leeuw JR, Ros WJ, et al. Pretreatment factors predicting quality of life after treatment for head and neck cancer. Head Neck 2000; 22:398-407.

40. Funk GF, Karnell LH, Whitehead S, et al. Free tissue transfer versus pedicled flap cost in head and neck cancer. Otolaryngol Head Neck Surg 2002;127:205-212.

41. Farwell DG, Reilly DF, Weymuller EA, Jr., et al. Predictors of perioperative complications in head and neck patients. Arch Otolaryngol Head Neck Surg 2002;128:505-511.

42. Charlson ME, Pompei P, Ales KL, et al. A new method of classifying prognostic comorbidity in longitudinal studies: development and validation. J Chronic Dis 1987;40:373-383.

43. Kaplan $\mathrm{MH}$, Feinstein AR. The importance of classifying initial comorbidity in evaluating the outcome of diabetes mellitus. J Chronic Dis 1974:27:387-404.

44. Piccirillo JF, Tierney RM, Costas I, et al. Prognostic importance of comorbidity in a hospital-based cancer registry. JAMA 2004;291: 2441-2447.

45. Patrick D, Erickson P. Health Status and Health Policy: Quality of Life in Health Care Evaluation and Resource Allocation. New York: Oxford University Press; 1993.

46. Yueh B. Measuring and Reporting Quality of Life in Head and Neck Cancer. McLean, Virginia. 2002.

47. Rogers SN, Gwanne S, Lowe D, et al. The addition of mood and anxiety domains to the University of Washington quality of life scale. Head Neck 2002;24:521-529.

48. Bjordal K, Hammerlid E, Ahlner-Elmqvist $\mathrm{M}$, et al. Quality of life in head and neck cancer patients: validation of the European Organization for Research and Treatment of Cancer Quality of Life Questionnaire-H\&N35 J Clin Oncol 1999:17:1008-1019.

49. Cella D. Manual for the Functional Assessment of Cancer Therapy (FACT) Measurement System (version 4). Chicago, IL: Rush Medical Center; 1997

50. List MA, D'Antonio LL, Cella DF, et al. The Performance Status Scale for Head and Neck Cancer Patients and the Functional Assessment of Cancer Therapy-Head and Neck Scale; a study of utility and validity. Cancer 1996;77:2294-2301.

51. Paleri V, Urbano TG, Mehanna H, et al. Management of neck metastases in head and neck cancer: United Kingdom National Multidisciplinary Guidelines. J Laryngol Otol 2016;130(S2):S161-S169.

52. Sun $R$, Tang $X$, Yang $Y$, et al. (18)FDG-PET/CT for the detection of regional nodal metastasis in patients with head and neck cancer: a metaanalysis. Oral Oncol 2015;51:314-320.

53. Kim SJ, Pak K, Kim K. Diagnostic accuracy of F-18 FDG PET or PET/CT for detection of lymph node metastasis in clinically node negative head and neck cancer patients; A systematic review and meta-analysis. Am J Otolaryngol 2019:40:297-305.

54. Kyzas PA, Evangelou E, Denaxa-Kyza D, et al. 18F-fluorodeoxyglucose positron emission tomography to evaluate cervical node metastases in patients with head and neck squamous cell carcinoma: a meta-analysis. J Natl Cancer Inst 2008;100:712-720.

55. YiX, Fan M, LiuY, et al. 18 FDG PET and PET-CT for the detection of bone metastases in patients with head and neck cancer. A meta-analysis. J Med Imaging Radiat Oncol 2013;57:674-679.

56. Rohde M, Nielsen AL, Johansen J, et al. Head-to-head comparison of chest X-ray/head and neck MRI, chest CT/head and neck MRI, and (18)FFDG PET/CT for detection of distant metastases and synchronous cancer in oral, pharyngeal, and laryngeal cancer. J Nucl Med 2017;58: 1919-1924.

57. Hosni A, Huang SH, Chiu K, et al. Predictors of early recurrence prior to planned postoperative radiation therapy for oral cavity squamous cell carcinoma and outcomes following salvage intensified radiation therapy. Int J Radiat Oncol Biol Phys 2019;103: 363-373.

58. Liauw SL, Mancuso AA, Amdur RJ, et al. Postradiotherapy neck dissection for lymph node-positive head and neck cancer: the use of computed tomography to manage the neck. J Clin Oncol 2006;24: $1421-1427$ 
59. Porceddu SV, Jarmolowski E, Hicks RJ, et al. Utility of positron emission tomography for the detection of disease in residual neck nodes after (chemo)radiotherapy in head and neck cancer. Head Neck 2005;27: 175-181.

60. Yao M, Smith RB, Hoffman HT, et al. Clinical significance of postradiotherapy [18F]-fluorodeoxyglucose positron emission tomography imaging in management of head-and-neck cancer-a long-term outcome report. Int J Radiat Oncol Biol Phys 2009;74:9-14.

61. Lango MN, Myers JN, Garden AS. Controversies in surgical management of the node-positive neck after chemoradiation. Semin Radiat Oncol 2009;19:24-28.

62. Kutler DI, Patel SG, Shah JP. The role of neck dissection following definitive chemoradiation. Oncology (Williston Park) 2004;18:993-998; discussion 999, 1003-1004, 1007.

63. Cheung PK, Chin RY, Eslick GD. Detecting residual/recurrent head neck squamous cell carcinomas using PET or PET/CT: systematic review and meta-analysis. Otolaryngol Head Neck Surg 2016;154:421-432.

64. Isles MG, McConkey C, Mehanna HM. A systematic review and metaanalysis of the role of positron emission tomography in the follow up of head and neck squamous cell carcinoma following radiotherapy or chemoradiotherapy. Clin Otolaryngol 2008;33:210-222.

65. Heineman TE, Kuan EC, St John MA. When should surveillance imaging be performed after treatment for head and neck cancer? Laryngoscope 2017;127:533-534.

66. Mehanna $\mathrm{H}$, Wong WL, McConkey $\mathrm{CC}$, et al. PET-CT surveillance versus neck dissection in advanced head and neck cancer. N Engl J Med 2016; 374:1444-1454.

67. Mehanna H, McConkey CC, Rahman JK, et al. PET-NECK: a multicentre randomised Phase III non-inferiority trial comparing a positron emission tomography-computerised tomography-guided watch-and-wait policy with planned neck dissection in the management of locally advanced (N2/N3) nodal metastases in patients with squamous cell head and neck cancer. Health Technol Assess 2017;21:1-122.

68. Corry J, Peters L, Fisher R, et al. N2-N3 neck nodal control without planned neck dissection for clinical/radiologic complete respondersresults of Trans Tasman Radiation Oncology Group Study 98.02. Head Neck 2008;30:737-742.

69. Lau H, Phan T, Mackinnon J, et al. Absence of planned neck dissection for the N2-N3 neck after chemoradiation for locally advanced squamous cell carcinoma of the head and neck. Arch Otolaryngol Head Neck Surg 2008;134:257-261.

70. Ong SC, Schöder H, Lee NY, et al. Clinical utility of 18F-FDG PET/CT in assessing the neck after concurrent chemoradiotherapy for locoregional advanced head and neck cancer. J Nucl Med 2008;49:532-540.

71. Nayak JV, Walvekar RR, Andrade RS, et al. Deferring planned neck dissection following chemoradiation for stage IV head and neck cancer: the utility of PET-CT. Laryngoscope 2007;117:2129-2134.

72. Abgral R, Querellou S, Potard G, et al. Does 18F-FDG PET/CT improve the detection of posttreatment recurrence of head and neck squamous cell carcinoma in patients negative for disease on clinical follow-up? J Nucl Med 2009;50:24-29.

73. Porceddu SV, Pryor DI, Burmeister E, et al. Results of a prospective study of positron emission tomography-directed management of residual nodal abnormalities in node-positive head and neck cancer after definitive radiotherapy with or without systemic therapy. Head Neck 2011; 33:1675-1682.

74. Ho AS, Tsao GJ, Chen FW, et al. Impact of positron emission tomography/computed tomography surveillance at 12 and 24 months for detecting head and neck cancer recurrence. Cancer 2013;119: 1349-1356.

75. Trosman SJ, Koyfman SA, Ward MC, et al. Effect of human papillomavirus on patterns of distant metastatic failure in oropharyngeal squamous cell carcinoma treated with chemoradiotherapy. JAMA Otolaryngol Head Neck Surg 2015;141:457-462.

76. Sheikhbahaei S, Taghipour M, Ahmad R, et al. Diagnostic accuracy of follow-up FDG PET or PET/CT in patients with head and neck cancer after definitive treatment: a systematic review and meta-analysis. AJR Am J Roentgenol 2015;205:629-639.

77. Dunsky KA, Wehrmann DJ, Osman MM, et al. PET-CT and the detection of the asymptomatic recurrence or second primary lesions in the treated head and neck cancer patient. Laryngoscope 2013;123: 2161-2164.

78. Aberle DR, Adams AM, Berg CD, et al. Reduced lung-cancer mortality with low-dose computed tomographic screening. N Engl J Med 2011; 365:395-409.
79. Humphrey LL, Deffebach M, Pappas M, et al. Screening for lung cancer with low-dose computed tomography: a systematic review to update the US Preventive services task force recommendation. Ann Intern Med 2013;159:411-420.

80. Cousins N, MacAulay $F$, Lang $H$, et al. A systematic review of interventions for eating and drinking problems following treatment for head and neck cancer suggests a need to look beyond swallowing and trismus. Oral Oncol 2013;49:387-400.

81. Locher JL, Bonner JA, Carroll WR, et al. Prophylactic percutaneous endoscopic gastrostomy tube placement in treatment of head and neck cancer: a comprehensive review and call for evidence-based medicine. JPEN J Parenter Enteral Nutr 2011;35:365-374.

82. Langius JA, van Dijk AM, Doornaert $P$, et al. More than $10 \%$ weight loss in head and neck cancer patients during radiotherapy is independently associated with deterioration in quality of life. Nutr Cancer 2013;65: 76-83.

83. August DA, Huhmann MB. American Society for Parenteral and Entera Nutrition (A.S.P.E.N.) Board of Directors. A.S.P.E.N. clinical guidelines: nutrition support therapy during adult anticancer treatment and in hematopoietic cell transplantation. JPEN J Parenter Enteral Nutr 2009;33: 472-500.

84. Garg S, Yoo J, Winquist E. Nutritional support for head and neck cancer patients receiving radiotherapy: a systematic review. Support Care Cancer 2010;18:667-677.

85. Rabeneck L, McCullough LB, Wray NP. Ethically justified, clinically comprehensive guidelines for percutaneous endoscopic gastrostomy tube placement. Lancet 1997;349:496-498.

86. Alshadwi A, Nadershah M, Carlson ER, et al. Nutritional considerations for head and neck cancer patients: a review of the literature. J Oral Maxillofac Surg 2013;71:1853-1860.

87. Raber-Durlacher JE, Brennan MT, Verdonck-de Leeuw IM, et al. Swallowing dysfunction in cancer patients. Support Care Cancer 2012; 20:433-443.

88. Wilson JA, Carding PN, Patterson JM. Dysphagia after nonsurgical head and neck cancer treatment: patients' perspectives. Otolaryngol Head Neck Surg 2011;145:767-771.

89. Tschiesner U. Preservation of organ function in head and neck cancer GMS Curr Top Otorhinolaryngol Head Neck Surg 2012;11:Doc07.

90. Bressan $\mathrm{V}$, Bagnasco A, Aleo G, et al. The life experience of nutrition impact symptoms during treatment for head and neck cancer patients: a systematic review and meta-synthesis. Support Care Cancer 2017;25: 1699-1712.

91. Roe JW, Carding PN, Rhys-Evans PH, et al. Assessment and management of dysphagia in patients with head and neck cancer who receive radiotherapy in the United Kingdom - a web-based survey. Oral Oncol 2012;48:343-348.

92. Russi EG, Corvò R, Merlotti A, et al. Swallowing dysfunction in head and neck cancer patients treated by radiotherapy: review and recommendations of the supportive task group of the Italian Association of Radiation Oncology. Cancer Treat Rev 2012;38:1033-1049.

93. Cnossen IC, de Bree R, Rinkel RN, et al. Computerized monitoring of patient-reported speech and swallowing problems in head and neck cancer patients in clinical practice. Support Care Cancer 2012;20: 2925-2931.

94. Epstein JB, Thariat J, Bensadoun RJ, et al. Oral complications of cancer and cancer therapy: from cancer treatment to survivorship. CA Cancer J Clin 2012;62:400-422.

95. Vera-Llonch $M$, Oster $G$, Hagiwara $M$, et al. Oral mucositis in patients undergoing radiation treatment for head and neck carcinoma. Cancer 2006;106:329-336

96. Elting LS, Cooksley CD, Chambers MS, et al. Risk, outcomes, and costs of radiation-induced oral mucositis among patients with head-and-neck malignancies. Int J Radiat Oncol Biol Phys 2007;68:1110-1120.

97. Trotti A, Bellm LA, Epstein JB, et al. Mucositis incidence, severity and associated outcomes in patients with head and neck cancer receiving radiotherapy with or without chemotherapy: a systematic literature review. Radiother Oncol 2003;66:253-262.

98. Bar Ad V, Weinstein G, Dutta PR, et al. Gabapentin for the treatment of pain syndrome related to radiation-induced mucositis in patients with head and neck cancer treated with concurrent chemoradiotherapy. Cancer 2010;116:4206-4213.

99. Sroussi HY, Epstein JB, Bensadoun RJ, et al. Common oral complications of head and neck cancer radiation therapy: mucositis, infections, saliva change, fibrosis, sensory dysfunctions, dental caries, periodontal disease, and osteoradionecrosis. Cancer Med 2017:6:2918-2931. 
100. Al-Ansari S, Zecha JA, Barasch A, et al. Oral mucositis induced by anticancer therapies. Curr Oral Health Rep 2015;2:202-211.

101. Lalla RV, Bowen J, Barasch A, et al. MASCC/ISOO clinical practice guidelines for the management of mucositis secondary to cancer therapy. Cancer 2014;120:1453-1461.

102. Sio TT, Le-Rademacher JG, Leenstra JL, et al. Effect of doxepin mouthwash or diphenhydramine-lidocaine-antacid mouthwash vs placebo on radiotherapy-related oral mucositis pain: the Alliance A221304 randomized clinical trial. JAMA 2019;321:1481-1490.

103. Bar Ad V, Weinstein G, Dutta PR, et al. Gabapentin for the treatment of pain related to radiation-induced mucositis in patients with head and neck tumors treated with intensity-modulated radiation therapy. Head Neck 2010;32:173-177.

104. Hermann GM, lovoli AJ, Platek AJ, et al. A single-institution, randomized, pilot study evaluating the efficacy of gabapentin and methadone for patients undergoing chemoradiation for head and neck squamous cell cancer. Cancer 2020;126:1480-1491.

105. Koyfman SA, Adelstein DJ. Enteral feeding tubes in patients undergoing definitive chemoradiation therapy for head-and-neck cancer: a critical review. Int J Radiat Oncol Biol Phys 2012;84:581-589.

106. Walker MP, Wichman $B$, Cheng AL, et al. Impact of radiotherapy dose on dentition breakdown in head and neck cancer patients. Pract Radiat Oncol 2011;1:142-148.

107. Jensen $S B$, Pedersen AM, Vissink $A$, et al. A systematic review of salivary gland hypofunction and xerostomia induced by cancer therapies: prevalence, severity and impact on quality of life. Support Care Cancer 2010;18:1039-1060.

108. Deng J, Jackson L, Epstein JB, et al. Dental demineralization and caries in patients with head and neck cancer. Oral Oncol 2015;51: 824-831.

109. Duarte VM, Liu YF, Rafizadeh S, et al. Comparison of dental health of patients with head and neck cancer receiving IMRT vs conventional radiation. Otolaryngol Head Neck Surg 2014;150:81-86.

110. Murdoch-Kinch CA, Kim HM, Vineberg KA, et al. Dose-effect relationships for the submandibular salivary glands and implications for their sparing by intensity modulated radiotherapy. Int J Radiat Oncol Biol Phys 2008;72:373-382.

111. Little M, Schipper M, Feng FY, et al. Reducing xerostomia after chemoIMRT for head-and-neck cancer: beyond sparing the parotid glands. Int J Radiat Oncol Biol Phys 2012;83:1007-1014

112. Chao KS. Protection of salivary function by intensity-modulated radiation therapy in patients with head and neck cancer. Semin Radiat Oncol 2002; 12(1, Suppl 1)20-25.

113. Murdoch-Kinch CA, Zwetchkenbaum S. Dental management of the head and neck cancer patient treated with radiation therapy. J Mich Dent Assoc 2011;93:28-37.

114. Studer G, Glanzmann C, Studer SP, et al. Risk-adapted dental care prior to intensity-modulated radiotherapy (IMRT). Schweiz Monatsschr Zahnmed 2011;121:216-229.

115. Ben-David MA, Diamante M, Radawski JD, et al. Lack of osteoradionecrosis of the mandible after intensity-modulated radiotherapy for head and neck cancer: likely contributions of both dental care and improved dose distributions. Int J Radiat Oncol Biol Phys 2007;68: 396-402.

116. Thariat J, Ramus $L$, Darcourt V, et al. Compliance with fluoride custom trays in irradiated head and neck cancer patients. Support Care Cancer 2012;20:1811-1814

117. Chang DT, Sandow PR, Morris CG, et al. Do pre-irradiation dental extractions reduce the risk of osteoradionecrosis of the mandible? Head Neck 2007;29:528-536.

118. Gomez DR, Estilo CL, Wolden SL, et al. Correlation of osteoradionecrosis and dental events with dosimetric parameters in intensity-modulated radiation therapy for head-and-neck cancer. Int J Radiat Oncol Biol Phys 2011;81:e207-e213.

119. Lee IJ, Koom WS, Lee CG, et al. Risk factors and dose-effect relationship for mandibular osteoradionecrosis in oral and oropharyngeal cancer patients. Int J Radiat Oncol Biol Phys 2009;75:1084-1091.

120. O'Dell K, Sinha U. Osteoradionecrosis. Oral Maxillofac Surg Clin North Am 2011;23:455-464.

121. Gevorgyan A, Wong K, Poon I, et al. Osteoradionecrosis of the mandible: a case series at a single institution. J Otolaryngol Head Neck Surg 2013;42:46.

122. Jacobson AS, Buchbinder D, Hu K, et al. Paradigm shifts in the management of osteoradionecrosis of the mandible. Oral Oncol 2010;46: 795-801.
123. Oh HK, Chambers MS, Martin JW, et al. Osteoradionecrosis of the mandible: treatment outcomes and factors influencing the progress of osteoradionecrosis. J Oral Maxillofac Surg 2009;67:1378-1386.

124. Sohn HO, Park EY, Jung YS, et al. Effects of professional oral hygiene care in patients with head-and-neck cancer during radiotherapy: A randomized clinical trial. Indian J Dent Res 2018;29:700-704.

125. Schiødt M, Hermund NU. Management of oral disease prior to radiation therapy. Support Care Cancer 2002;10:40-43.

126. Rhodus NL, Bereuter J. Clinical evaluation of a commercially available oral moisturizer in relieving signs and symptoms of xerostomia in postirradiation head and neck cancer patients and patients with Sjögren's syndrome. J Otolaryngol 2000;29:28-34.

127. Singh ML, Papas AS. Long-term clinical observation of dental caries in salivary hypofunction patients using a supersaturated calciumphosphate remineralizing rinse. J Clin Dent 2009;20:87-92.

128. Epstein JB, Schubert MM. Synergistic effect of sialagogues in management of xerostomia after radiation therapy. Oral Surg Oral Med Ora Pathol 1987;64:179-182.

129. Gorsky M, Epstein JB, Parry J, et al. The efficacy of pilocarpine and bethanechol upon saliva production in cancer patients with hyposalivation following radiation therapy. Oral Surg Oral Med Oral Pathol Oral Radiol Endod 2004;97:190-195.

130. Johnson JT, Ferretti GA, Nethery WJ, et al. Oral pilocarpine for postirradiation xerostomia in patients with head and neck cancer. $N$ Engl $J$ Med 1993;329:390-395.

131. Dholam KP, Somani PP, Prabhu SD, et al. Effectiveness of fluoride varnish application as cariostatic and desensitizing agent in irradiated head and neck cancer patients [published online June 13, 2013]. Int J Dent 2013 2013:824982

132. Epstein JB, van der Meij EH, Lunn R, et al. Effects of compliance with fluoride gel application on caries and caries risk in patients after radiation therapy for head and neck cancer. Oral Surg Oral Med Oral Pathol Oral Radiol Endod 1996;82:268-275.

133. Horiot JC, Schraub S, Bone MC, et al. Dental preservation in patients irradiated for head and neck tumours: A 10-year experience with topical fluoride and a randomized trial between two fluoridation methods. Radiother Oncol 1983;1:77-82.

134. Fleming TJ. Use of topical fluoride by patients receiving cancer therapy. Curr Probl Cancer 1983;7:37-41.

135. Beumer J III, Harrison R, Sanders B, et al. Postradiation dental extractions: a review of the literature and a report of 72 episodes. Head Neck Surg 1983;6:581-586.

136. Shulman DH, Shipman B, Willis FB. Treating trismus with dynamic splinting: a case report. J Oral Sci 2009;51:141-144.

137. Teguh DN, Levendag PC, Voet $\mathrm{P}$, et al. Trismus in patients with oropharyngeal cancer: relationship with dose in structures of mastication apparatus. Head Neck 2008;30:622-630.

138. Brunello DL, Mandikos MN. The use of a dynamic opening device in the treatment of radiation induced trismus. Aust Prosthodont J 1995;9: 45-48.

139. Epstein JB, Emerton S, Le ND, et al. A double-blind crossover trial of Oral Balance gel and Biotene toothpaste versus placebo in patients with xerostomia following radiation therapy. Oral Oncol 1999;35: 132-137

140. Papas A, Russell D, Singh M, et al. Caries clinical trial of a remineralising toothpaste in radiation patients. Gerodontology 2008;25:76-88.

141. Adelstein DJ, Li Y, Adams GL, et al. An intergroup phase III comparison of standard radiation therapy and two schedules of concurrent chemoradiotherapy in patients with unresectable squamous cell head and neck cancer. J Clin Oncol 2003;21:92-98.

142. Lo TC, Wiley AL, Jr., Ansfield FJ, et al. Combined radiation therapy and 5-fluorouracil for advanced squamous cell carcinoma of the oral cavity and oropharynx: a randomized study. AJR Am J Roentgenol 1976;126: 229-235

143. Sanchíz F, Millá A, Torner J, et al. Single fraction per day versus two fractions per day versus radiochemotherapy in the treatment of head and neck cancer. Int J Radiat Oncol Biol Phys 1990;19:1347-1350.

144. Browman GP, Cripps C, Hodson DI, et al. Placebo-controlled randomized trial of infusional fluorouracil during standard radiotherapy in locally advanced head and neck cancer. J Clin Oncol 1994;12: 2648-2653.

145. Smid L, Lesnicar H, Zakotnik B et al. Radiotherapy, combined with simultaneous chemotherapy with mitomycin $\mathrm{C}$ and bleomycin for inoperable head and neck cancer--preliminary report. Int J Radiat Onco Biol Phys 1995:32:769-775. 
146. Bachaud JM, Cohen-Jonathan E, Alzieu C, et al. Combined postoperative radiotherapy and weekly cisplatin infusion for locally advanced head and neck carcinoma: final report of a randomized trial. Int J Radiat Oncol Biol Phys 1996;36:999-1004

147. Merlano $M$, Benasso $M$, Corvò $R$, et al. Five-year update of a randomized trial of alternating radiotherapy and chemotherapy compared with radiotherapy alone in treatment of unresectable squamous cell carcinoma of the head and neck. J Natl Cancer Inst 1996;88: 583-589.

148. Brizel DM, Albers ME, Fisher SR, et al. Hyperfractionated irradiation with or without concurrent chemotherapy for locally advanced head and neck cancer. N Engl J Med 1998;338:1798-1804.

149. Wendt TG, Grabenbauer GG, Rödel CM, et al. Simultaneous radiochemotherapy versus radiotherapy alone in advanced head and neck cancer: a randomized multicenter study. J Clin Oncol 1998;16: 1318-1324.

150. Jeremic B, Shibamoto $Y$, Milicic B, et al. Hyperfractionated radiation therapy with or without concurrent low-dose daily cisplatin in locally advanced squamous cell carcinoma of the head and neck: a prospective randomized trial. J Clin Oncol 2000;18:1458-1464.

151. Munro AJ. An overview of randomised controlled trials of adjuvant chemotherapy in head and neck cancer. Br J Cancer 1995;71:83-91.

152. El-Sayed S, Nelson N. Adjuvant and adjunctive chemotherapy in the management of squamous cell carcinoma of the head and neck region. A meta-analysis of prospective and randomized trials. J Clin Oncol 1996; 14:838-847.

153. Pignon JP, Bourhis J, Domenge C, et al. Chemotherapy added to locoregional treatment for head and neck squamous-cell carcinoma: three meta-analyses of updated individual data. MACH-NC Collaborative Group. Meta-analysis of chemotherapy on head and neck cancer. Lancet 2000;355:949-955

154. Bourhis J, Amand C, Pignon J-P. Update of MACH-NC (meta-analysis of chemotherapy in head \& neck cancer) database focused on concomitant chemoradiotherapy [abstract]. J Clin Oncol 2004;22(Suppl 14):Abstract 5505.

155. Pignon JP, le Maître A, Bourhis J. Meta-analyses of chemotherapy in head and neck cancer (MACH-NC): an update. Int J Radiat Oncol Biol Phys 2007;69(Suppl)S112-S114.

156. Sher DJ, Adelstein DJ, Bajaj GK, et al. Radiation therapy for oropharyngeal squamous cell carcinoma: executive summary of an ASTRO Evidence-Based Clinical Practice Guideline. Pract Radiat Oncol 2017;7: 246-253.

157. Rubin Grandis J, Melhem MF, Gooding WE, et al. Levels of TGF-alpha and EGFR protein in head and neck squamous cell carcinoma and patient survival. J Natl Cancer Inst 1998;90:824-832.

158. Zhu X, Zhang F, Zhang W, et al. Prognostic role of epidermal growth factor receptor in head and neck cancer: a meta-analysis. J Surg Oncol 2013;108:387-397.

159. Bonner JA, Harari PM, Giralt J, et al. Radiotherapy plus cetuximab for squamous-cell carcinoma of the head and neck. N Engl J Med 2006;354: 567-578.

160. Bonner JA, Harari PM, Giralt J, et al. Radiotherapy plus cetuximab for locoregionally advanced head and neck cancer: 5 -year survival data from a phase 3 randomised trial, and relation between cetuximab-induced rash and survival. Lancet Oncol 2010;11:21-28.

161. Ang KK, Zhang Q, Rosenthal DI, et al. Randomized phase III trial of concurrent accelerated radiation plus cisplatin with or without cetuximab for stage III to IV head and neck carcinoma: RTOG 0522. J Clin Oncol 2014;32:2940-2950.

162. Tao Y, Auperin A, Sire $C$, et al. Improved outcome by adding concurrent chemotherapy to cetuximab and radiotherapy for locally advanced head and neck carcinomas: results of the GORTEC 2007-01 phase III randomized trial [published online June 7, 2018]. J Clin Oncol, doi: 10.1200/JCO.2017.76.2518

163. Gillison ML, Trotti AM, Harris J, et al. Radiotherapy plus cetuximab or cisplatin in human papillomavirus-positive oropharyngeal cancer (NRG Oncology RTOG 1016): a randomised, multicentre, non-inferiority trial. Lancet 2019;393:40-50.

164. Mehanna H, Robinson M, Hartley A, et al. Radiotherapy plus cisplatin or cetuximab in low-risk human papillomavirus-positive oropharyngeal cancer (De-ESCALaTE HPV): an open-label randomised controlled phase 3 trial. Lancet 2019;393:51-60.

165. Forastiere AA, Zhang Q, Weber RS, et al. Long-term results of RTOG 9111: a comparison of three nonsurgical treatment strategies to preserve the larynx in patients with locally advanced larynx cancer. J Clin Onco 2013;31:845-852.

166. Bourhis J, Sire C, Graff P, et al. Concomitant chemoradiotherapy versus acceleration of radiotherapy with or without concomitant chemotherapy in locally advanced head and neck carcinoma (GORTEC 99-02): an openlabel phase 3 randomised trial. Lancet Oncol 2012;13:145-153.

167. Cohen EE, Karrison TG, Kocherginsky M, et al. Phase III randomized trial of induction chemotherapy in patients with N2 or N3 locally advanced head and neck cancer. J Clin Oncol 2014;32:2735-2743.

168. Haddad R, O'Neill A, Rabinowits G, et al. Induction chemotherapy followed by concurrent chemoradiotherapy (sequential chemoradiotherapy) versus concurrent chemoradiotherapy alone in locally advanced head and neck cancer (PARADIGM): a randomised phase 3 trial. Lancet Oncol 2013;14:257-264.

169. Magrini SM, Buglione $M$, Corvò $R$, et al. Cetuximab and radiotherapy versus cisplatin and radiotherapy for locally advanced head and neck cancer: a randomized phase II trial. J Clin Oncol 2016;34:427-435.

170. Garden AS, Harris J, Vokes EE, et al. Preliminary results of Radiation Therapy Oncology Group 97-03: a randomized phase ii trial of concurrent radiation and chemotherapy for advanced squamous cell carcinomas of the head and neck. J Clin Oncol 2004;22:2856-2864.

171. Beckmann GK, Hoppe F, Pfreundner L, et al. Hyperfractionated accelerated radiotherapy in combination with weekly cisplatin for locally advanced head and neck cancer. Head Neck 2005;27:36-43.

172. Medina JA, Rueda A, de Pasos AS, et al. A phase II study of concomitant boost radiation plus concurrent weekly cisplatin for locally advanced unresectable head and neck carcinomas. Radiother Oncol 2006;79: 34-38.

173. Suntharalingam M, Haas ML, Conley BA, et al. The use of carboplatin and paclitaxel with daily radiotherapy in patients with locally advanced squamous cell carcinomas of the head and neck. Int J Radiat Oncol Bio Phys 2000;47:49-56.

174. Taylor SG IV, Murthy AK, Vannetzel JM, et al. Randomized comparison of neoadjuvant cisplatin and fluorouracil infusion followed by radiation versus concomitant treatment in advanced head and neck cancer. J Clin Oncol 1994;12:385-395

175. Sun XS, Michel C, Babin E, et al. Approach to oligometastatic disease in head and neck cancer, on behalf of the GORTEC. Future Oncol 2018;14 877-889.

176. Bonomo P, Greto D, Desideri I, et al. Clinical outcome of stereotactic body radiotherapy for lung-only oligometastatic head and neck squamous cell carcinoma: Is the deferral of systemic therapy a potential goal? Oral Oncol 2019;93:1-7

177. Bates JE, De Leo AN, Morris CG, et al. Oligometastatic squamous cell carcinoma of the head and neck treated with stereotactic body ablative radiotherapy: Single-institution outcomes. Head Neck 2019;41: 2309-2314.

178. Fury MG, Pfister DG. Current recommendations for systemic therapy of recurrent and/or metastatic head and neck squamous cell cancer. J Nat Compr Canc Netw 2011;9:681-689.

179. Molin Y, Fayette J. Current chemotherapies for recurrent/metastatic head and neck cancer. Anticancer Drugs 2011;22:621-625.

180. Hoffmann TK. Systemic therapy strategies for head-neck carcinomas: Current status. GMS Curr Top Otorhinolaryngol Head Neck Surg 2012; 11:Doc03.

181. Price KA, Cohen EE. Current treatment options for metastatic head and neck cancer. Curr Treat Options Oncol 2012;13:35-46.

182. Gibson MK, Li Y, Murphy B, et al. Randomized phase III evaluation of cisplatin plus fluorouracil versus cisplatin plus paclitaxel in advanced head and neck cancer (E1395): an intergroup trial of the Eastern Cooperative Oncology Group. J Clin Oncol 2005;23:3562-3567.

183. Forastiere AA, Metch B, Schuller DE, et al. Randomized comparison of cisplatin plus fluorouracil and carboplatin plus fluorouracil versus methotrexate in advanced squamous-cell carcinoma of the head and neck: a Southwest Oncology Group study. J Clin Oncol 1992;10: 1245-1251.

184. Jacobs C, Lyman G, Velez-García E, et al. A phase III randomized study comparing cisplatin and fluorouracil as single agents and in combination for advanced squamous cell carcinoma of the head and neck. J Clin Oncol 1992;10:257-263

185. Browman GP, Cronin L. Standard chemotherapy in squamous cell head and neck cancer: what we have learned from randomized trials. Semin Oncol 1994;21:311-319.

186. Clavel M, Vermorken JB, Cognetti F, et al. Randomized comparison of cisplatin, methotrexate, bleomycin and vincristine $(C A B O)$ versus 
cisplatin and 5-fluorouracil (CF) versus cisplatin (C) in recurrent or metastatic squamous cell carcinoma of the head and neck. A phase III study of the EORTC Head and Neck Cancer Cooperative Group. Ann Oncol 1994:5:521-526.

187. Vermorken JB, Mesia R, Rivera F, et al. Platinum-based chemotherapy plus cetuximab in head and neck cancer. N Engl J Med 2008;359: 1116-1127.

188. Burtness B, Harrington KJ, Greil R, et al. Pembrolizumab alone or with chemotherapy versus cetuximab with chemotherapy for recurrent or metastatic squamous cell carcinoma of the head and neck (KEYNOTE048): a randomised, open-label, phase 3 study. Lancet 2019;394: 1915-1928.

189. Cohen EEW, Soulières D, Le Tourneau C, et al.KEYNOTE-040 investigators. Pembrolizumab versus methotrexate, docetaxel, or cetuximab for recurrent or metastatic head-and-neck squamous cell carcinoma (KEYNOTE-040): a randomised, open-label, phase 3 study. Lancet 2019; 393:156-167.

190. Ferris RL, Blumenschein G, Jr., Fayette J, et al. Nivolumab for recurrent squamous-cell carcinoma of the head and neck. N Engl J Med 2016;375: 1856-1867.

191. Samlowski WE, Moon J, Kuebler JP, et al. Evaluation of the combination of docetaxel/carboplatin in patients with metastatic or recurrent squamous cell carcinoma of the head and neck (SCCHN): a Southwest Oncology Group Phase II study. Cancer Invest 2007;25: 182-188.

192. Burtness B, Goldwasser MA, Flood W, et al. Phase III randomized trial of cisplatin plus placebo compared with cisplatin plus cetuximab in metastatic/recurrent head and neck cancer: an Eastern Cooperative Oncology Group study. J Clin Oncol 2005;23:8646-8654.

193. Bossi P, Miceli R, Locati LD, et al. A randomized, phase 2 study of cetuximab plus cisplatin with or without paclitaxel for the first-line treatment of patients with recurrent and/or metastatic squamous cell carcinoma of the head and neck. Ann Oncol 2017;28:2820-2826.

194. Guigay J, Fayette J, Dillies A-F, et al. Cetuximab, docetaxel, and cisplatin (TPEx) as first-line treatment in patients with recurrent or metastatic (R/M) squamous cell carcinoma of the head and neck (SCCHN): Final results of phase II trial GORTEC 2008-03 [abstract]. J Clin Oncol 2012;30(Suppl 15):Abstract 5505

195. Herbst RS, Arquette M, Shin DM, et al. Phase II multicenter study of the epidermal growth factor receptor antibody cetuximab and cisplatin for recurrent and refractory squamous cell carcinoma of the head and neck. J Clin Oncol 2005;23:5578-5587.

196. Tahara M, Kiyota N, Yokota T, et al. Phase II trial of combination treatment with paclitaxel, carboplatin and cetuximab (PCE) as first-line treatment in patients with recurrent and/or metastatic squamous cell carcinoma of the head and neck (CSPOR-HNO2). Ann Oncol 2018;29: 1004-1009.

197. Grau JJ, Caballero M, Verger E, et al. Weekly paclitaxel for platinresistant stage IV head and neck cancer patients. Acta Otolaryngol 2009; 129:1294-1299.

198. Guardiola E, Peyrade F, Chaigneau L, et al. Results of a randomised phase II study comparing docetaxel with methotrexate in patients with recurrent head and neck cancer. Eur J Cancer 2004:40:2071-2076.

199. Catimel G, Verweij J, Mattijssen V, et al.EORTC Early Clinical Trials Group. Docetaxel (Taxotere): an active drug for the treatment of patients with advanced squamous cell carcinoma of the head and neck. Ann Oncol 1994;5:533-537.

200. Stewart JS, Cohen EE, Licitra L, et al. Phase III study of gefitinib compared with intravenous methotrexate for recurrent squamous cell carcinoma of the head and neck [corrected]. [corrected] J Clin Oncol 2009; 27:1864-1871; erratum in: J Clin Oncol 2009;27:3410.

201. Haigentz M, Jr., Hartl DM, Silver CE, et al. Distant metastases from head and neck squamous cell carcinoma. Part III. Treatment. Oral Oncol 2012; 48:787-793

202. Martinez-Trufero J, Isla D, Adansa JC, et al. Phase II study of capecitabine as palliative treatment for patients with recurrent and metastatic squamous head and neck cancer after previous platinum-based treatment. $\mathrm{Br}$ J Cancer 2010;102:1687-1691.

203. Vermorken JB, Trigo J, Hitt R, et al. Open-label, uncontrolled, multicenter phase II study to evaluate the efficacy and toxicity of cetuximab as a single agent in patients with recurrent and/or metastatic squamous cell carcinoma of the head and neck who failed to respond to platinumbased therapy. J Clin Oncol 2007;25:2171-2177.

204. Colevas AD. Chemotherapy options for patients with metastatic or recurrent squamous cell carcinoma of the head and neck. J Clin Oncol $2006 ; 24: 2644-2652$
205. Forastiere AA, Shank D, Neuberg D, et al. Final report of a phase II evaluation of paclitaxel in patients with advanced squamous cell carcinoma of the head and neck: an Eastern Cooperative Oncology Group trial (PA390). Cancer 1998;82:2270-2274.

206. Seiwert TY, Burtness B, Mehra R, et al. Safety and clinical activity of pembrolizumab for treatment of recurrent or metastatic squamous cell carcinoma of the head and neck (KEYNOTE-012): an open-label, multicentre, phase 1b trial. Lancet Oncol 2016;17:956-965.

207. Chow LQM, Haddad R, Gupta S, et al. Antitumor activity of pembrolizumab in biomarker-unselected patients with recurrent and/or metastatic head and neck squamous cell carcinoma: results from the phase Ib KEYNOTE-012 expansion cohort. J Clin Oncol 2016;34: 3838-3845.

208. Mehra R, Seiwert TY, Gupta S, et al. Efficacy and safety of pembrolizumab in recurrent/metastatic head and neck squamous cell carcinoma: pooled analyses after long-term follow-up in KEYNOTE-012. Br J Cancer 2018, 119:153-159.

209. Bauml J, Seiwert TY, Pfister DG, et al. Pembrolizumab for platinum- and cetuximab-refractory head and neck cancer: results from a single-arm, phase II study. J Clin Oncol 2017;35:1542-1549.

210. Machiels JP, Haddad RI, Fayette J, et al. Afatinib versus methotrexate as second-line treatment in patients with recurrent or metastatic squamouscell carcinoma of the head and neck progressing on or after platinumbased therapy (LUX-Head \& Neck 1): an open-label, randomised phase 3 trial. Lancet Oncol 2015;16:583-594.

211. Clement PM, Gauler T, Machiels JP, et al. Afatinib versus methotrexate in older patients with second-line recurrent and/or metastatic head and neck squamous cell carcinoma: subgroup analysis of the LUX-Head \& Neck 1 trial. Ann Oncol 2016;27:1585-1593.

212. Seiwert TY, Fayette J, Cupissol D, et al. A randomized, phase II study of afatinib versus cetuximab in metastatic or recurrent squamous cell carcinoma of the head and neck. Ann Oncol 2014;25:1813-1820.

213. Spiro RH. Salivary neoplasms: overview of a 35-year experience with 2,807 patients. Head Neck Surg 1986;8:177-184.

214. Bron LP, Traynor SJ, McNeil EB, et al. Primary and metastatic cancer of the parotid: comparison of clinical behavior in 232 cases. Laryngoscope 2003;113:1070-1075.

215. Nagliati M, Bolner A, Vanoni $\mathrm{V}$, et al. Surgery and radiotherapy in the treatment of malignant parotid tumors: a retrospective multicenter study. Tumori 2009;95:442-448.

216. Garden AS, Weber RS, Morrison WH, et al. The influence of positive margins and nerve invasion in adenoid cystic carcinoma of the head and neck treated with surgery and radiation. Int J Radiat Oncol Biol Phys 1995;32:619-626.

217. Bell RB, Dierks EJ, Homer L, et al. Management and outcome of patients with malignant salivary gland tumors. J Oral Maxillofac Surg 2005;63: 917-928.

218. Copelli C, Bianchi B, Ferrari $S$, et al. Malignant tumors of intraoral minor salivary glands. Oral Oncol 2008;44:658-663.

219. Vander Poorten V, Bradley PJ, Takes RP, et al. Diagnosis and management of parotid carcinoma with a special focus on recent advances in molecular biology. Head Neck 2012;34:429-440.

220. Timoshchuk MA, Dekker P, Hippe DS, et al. The efficacy of neutron radiation therapy in treating salivary gland malignancies. Oral Oncol 2019;88:51-57

221. Laramore GE, Krall JM, Griffin TW, et al. Neutron versus photon irradiation for unresectable salivary gland tumors: final report of an RTOGMRC randomized clinical trial. Int J Radiat Oncol Biol Phys 1993;27: 235-240.

222. Stannard C, Vernimmen F, Carrara H, et al. Malignant salivary gland tumours: can fast neutron therapy results point the way to carbon ion therapy? Radiother Oncol 2013;109:262-268.

223. Cederblad L, Johansson S, Enblad G, et al. Cancer of the parotid gland long-term follow-up. A single centre experience on recurrence and survival. Acta Oncol 2009;48:549-555.

224. Eppsteiner RW, Fowlkes JW, Anderson CM, et al. Aggressive salivary malignancies at early stage: outcomes and implications for treatment. Ann Otol Rhinol Laryngol 2017;126:525-529.

225. Terhaard $\mathrm{CH}$, Lubsen $\mathrm{H}$, Rasch $\mathrm{CR}$, et al. The role of radiotherapy in the treatment of malignant salivary gland tumors. Int J Radiat Oncol Biol Phys 2005;61:103-111.

226. Tanvetyanon T, Qin D, Padhya T, et al. Outcomes of postoperative concurrent chemoradiotherapy for locally advanced major salivary gland carcinoma. Arch Otolaryngol Head Neck Surg 2009;135 687-692. 
227. Williams L, Thompson LD, Seethala RR, et al. Salivary duct carcinoma: the predominance of apocrine morphology, prevalence of histologic variants, and androgen receptor expression. Am J Surg Pathol 2015;39: 705-713.

228. Udager AM, Chiosea SI. Salivary duct carcinoma: an update on morphologic mimics and diagnostic use of androgen receptor immunohistochemistry. Head Neck Pathol 2017;11:288-294.

229. Simpson RH. Salivary duct carcinoma: new developments--morphological variants including pure in situ high grade lesions; proposed molecular classification. Head Neck Pathol 2013; 7(Suppl 1)S48-58.

230. Fan CY, Wang J, Barnes EL. Expression of androgen receptor and prostatic specific markers in salivary duct carcinoma: an immunohistochemical analysis of 13 cases and review of the literature. Am J Surg Pathol 2000;24:579-586.

231. Schmitt NC, Kang H, Sharma A. Salivary duct carcinoma: an aggressive salivary gland malignancy with opportunities for targeted therapy. Oral Oncol 2017;74:40-48.

232. Boon E, van Boxtel W, Buter J, et al. Androgen deprivation therapy for androgen receptor-positive advanced salivary duct carcinoma: a nationwide case series of 35 patients in The Netherlands. Head Neck 2018; 40:605-613.

233. Yamamoto N, Minami S, Fujii M. Clinicopathologic study of salivary duct carcinoma and the efficacy of androgen deprivation therapy. Am J Otolaryngol 2014;35:731-735.

234. Fushimi C, Tada $Y$, Takahashi $H$, et al. A prospective phase II study of combined androgen blockade in patients with androgen receptorpositive metastatic or locally advanced unresectable salivary gland carcinoma. Ann Oncol 2018;29:979-984.

235. Drilon A, Laetsch TW, Kummar S, et al. Efficacy of larotrectinib in TRK fusion-positive cancers in adults and children. N Engl J Med 2018;378: 731-739.

236. Hong DS, Bauer TM, Lee JJ, et al. Larotrectinib in adult patients with solid tumours: a multi-centre, open-label, phase I dose-escalation study. Ann Oncol 2019;30:325-331.

237. Doebele RC, Drilon A, Paz-Ares L, et al. Entrectinib in patients with advanced or metastatic NTRK fusion-positive solid tumours: integrated analysis of three phase 1-2 trials. Lancet Oncol 2020;21:271-282.

238. Gilbert MR, Sharma A, Schmitt NC, et al. A 20-year review of 75 cases of salivary duct carcinoma. JAMA Otolaryngol Head Neck Surg 2016;142: 489-495.

239. Thorpe $L M$, Schrock AB, Erlich RL, et al. Significant and durable clinical benefit from trastuzumab in 2 patients with HER2-amplified salivary gland cancer and a review of the literature. Head Neck 2017;39: E40-E44.

240. Li BT, Shen R, Offin M et al. Ado-trastuzumab emtansine in patients with HER2 amplified salivary gland cancers (SGCs): results from a phase II basket trial. J Clin Oncol 2019;37(15_suppl):6001-6003.

241. Corrêa TS, Matos GDR, Segura M, et al. Second-line treatment of HER2 positive salivary gland tumor: ado-trastuzumab emtansine (T-DM1) after progression on trastuzumab. Case Rep Oncol 2018;11:252-257.

242. Jhaveri KL, Wang XV, Makker $\mathrm{V}$, et al. Ado-trastuzumab emtansine (T-DM1) in patients with HER2-amplified tumors excluding breast and gastric/gastroesophageal junction (GEJ) adenocarcinomas: results from the NCl-MATCH trial (EAY131) subprotocol Q. Ann Oncol 2019;30: 1821-1830.

243. Skalova A. Mammary analogue secretory carcinoma of salivary gland origin: an update and expanded morphologic and immunohistochemical spectrum of recently described entity. Head Neck Pathol 2013; 7(Suppl 1)S30-S36.

244. Debaere D, Vander Poorten V, Nuyts S, et al. Cyclophosphamide, doxorubicin, and cisplatin in advanced salivary gland cancer. B-ENT 2011;7:1-6.

245. Licitra L, Cavina R, Grandi C, et al. Cisplatin, doxorubicin and cyclophosphamide in advanced salivary gland carcinoma: a phase II trial of 22 patients. Ann Oncol 1996;7:640-642.

246. Airoldi M, Pedani F, Succo G, et al. Phase II randomized trial comparing vinorelbine versus vinorelbine plus cisplatin in patients with recurrent salivary gland malignancies. Cancer 2001;91:541-547.

247. Tchekmedyian V, Sherman EJ, Dunn L, et al. Phase II study of lenvatinib in patients with progressive, recurrent or metastatic adenoid cystic carcinoma. J Clin Oncol 2019;37:1529-1537.

248. Locati LD, Cavalieri S, Bergamini C, et al. Phase II trial with axitinib in recurrent and/or metastatic salivary gland cancers of the upper aerodigestive tract. Head Neck 2019;41:3670-3676.

249. Thomson DJ, Silva P, Denton K, et al. Phase II trial of sorafenib in advanced salivary adenoid cystic carcinoma of the head and neck. Head Neck 2015;37:182-187.

250. Chau NG, Hotte SJ, Chen EX, et al. A phase II study of sunitinib in recurrent and/or metastatic adenoid cystic carcinoma (ACC) of the salivary glands: current progress and challenges in evaluating molecularly targeted agents in ACC. Ann Oncol 2012;23:1562-1570.

251. Keam B, Kim SB, Shin SH, et al. Phase 2 study of dovitinib in patients with metastatic or unresectable adenoid cystic carcinoma. Cancer 2015;121. 2612-2617. 


\section{Individual Disclosures for the NCCN Head and Neck Cancers Panel}

\begin{tabular}{|c|c|c|c|c|}
\hline Panel Member & $\begin{array}{l}\text { Clinical Research Support/Data Safety } \\
\text { Monitoring Board }\end{array}$ & $\begin{array}{l}\text { Scientific Advisory Boards, Consultant, } \\
\text { or Expert Witness }\end{array}$ & $\begin{array}{l}\text { Promotional Advisory } \\
\text { Boards, Consultant, or } \\
\text { Speakers Bureau }\end{array}$ & Specialties \\
\hline David Adelstein, MD & Innogene-Kalbiotech & None & None & Medical Oncology \\
\hline Douglas Adkins, MD & $\begin{array}{l}\text { Bristol-Myers Squibb Company; Celgene Corporation; } \\
\text { Celldex Therapeutics; Eisai Inc.; Eli Lilly and Company; } \\
\text { Exelixis Inc.; Kura Oncology, Inc.; Merck \& Co., Inc.; Pfizer } \\
\text { Inc.; and Roche Laboratories, Inc. }\end{array}$ & Kura Oncology, Inc., and Merck \& Co., Inc. & None & Medical Oncology \\
\hline Yoshimi Anzai, MD, MPH & None & None & None & Diagnostic Radiology \\
\hline David M. Brizel, MD & Biomimetix & sanofi-aventis U.S. & None & Radiation Oncology \\
\hline Justine Y. Bruce MD & $\begin{array}{l}\text { Astellas Pharma US, Inc.;Incyte Corporation; Kura } \\
\text { Oncology, Inc.; Lilly; Merck \& Co., Inc.; Seattle Genetics, } \\
\text { Inc.; and Sensei Biotherapeutics }\end{array}$ & Genzyme Corporation & None & Medical Oncology \\
\hline Paul M. Busse, MD, PhD & None & None & None & Radiation Oncology \\
\hline $\begin{array}{l}\text { Jimmy J. Caudell, MD, } \\
\text { PhD }\end{array}$ & Varian Medical Systems, Inc. & None & None & Radiation Oncology \\
\hline Anthony J. Cmelak, MD & None & None & None & Radiation Oncology \\
\hline A. Dimitrios Colevas, MD & $\begin{array}{l}\text { AbbVie, Inc.; Atara Biotherapeutics; Bristol-Myers Squibb } \\
\text { Company; Cellsight Technologies, Inc.; Cue Biopharma; } \\
\text { Cullinan Oncology; Exelixis Inc.; Innate Pharma; IQVIA; PDS } \\
\text { Biotechnology Corporation; PRA Health Sciences; Rakuten; } \\
\text { and Tessa Therapeutics }\end{array}$ & None & None & Medical Oncology \\
\hline David W. Eisele, MD & None & None & None & $\begin{array}{l}\text { Surgery/Surgical Oncology, and } \\
\text { Otolaryngology }\end{array}$ \\
\hline Moon Fenton, MD, PhD & None & None & None & Medical Oncology \\
\hline Robert L. Foote, MD & Hitachi, Ltd. & $\begin{array}{l}\text { Alliance for Proton Therapy Access, and Cancer Terminator } \\
\text { Foundation }\end{array}$ & None & Radiation Oncology \\
\hline Thomas Galloway, MD & None & None & None & Radiation Oncology \\
\hline $\begin{array}{l}\text { Maura L. Gillison, MD, } \\
\text { PhD }\end{array}$ & BioMimetix & $\begin{array}{l}\text { Bayer HealthCare; BioNTech; EMD Serono, Inc.; Kura } \\
\text { Oncology; Merck \& Co., Inc.; Roche Laboratories, Inc.; and } \\
\text { Shattuck Labs }\end{array}$ & None & Medical Oncology \\
\hline Robert I. Haddad, MD & $\begin{array}{l}\text { Bristol-Myers Squibb Company; Genentech, Inc.; ISA } \\
\text { Therapeutics; Kura Oncology, Inc.; Merck \& Co., Inc.; } \\
\text { Nanobiotix; and Pfizer Inc. }\end{array}$ & $\begin{array}{l}\text { Bayer HealthCare; Bristol-Myers Squibb Company; Eisai } \\
\text { Inc.; Genentech, Inc.; GlaxoSmithKline; Glenmark } \\
\text { Pharmaceuticals; Immunomic Therapeutics; Loxo; Merck \& } \\
\text { Co., Inc.; Nanobiotix; and Pfizer Inc. }\end{array}$ & None & Medical Oncology \\
\hline Wesley L. Hicks, Jr., MD & None & None & None & Surgery/Surgical Oncology \\
\hline Ying J. Hitchcock, MD & None & None & None & Radiation Oncology \\
\hline $\begin{array}{l}\text { Antonio Jimeno, MD, } \\
\mathrm{PhD}^{\circ}\end{array}$ & $\begin{array}{l}\text { Bristol-Myers Squibb Company; Genocea Biosciences, Inc.; } \\
\text { Holystone; lovance Biotherapeutics; Merck \& Co., Inc.; } \\
\text { Moderna; and SOZ Biotech }\end{array}$ & None & None & Medical Oncology \\
\hline Debra Leizman, MD & None & None & None & Internal Medicine \\
\hline Ellie Maghami, MD & None & None & None & $\begin{array}{l}\text { Surgery/Surgical Oncology, and } \\
\text { Otolaryngology }\end{array}$ \\
\hline Loren K. Mell, MD & AstraZeneca Pharmaceuticals LP, and Merck \& Co., Inc. & None & None & Radiation Oncology \\
\hline Bharat B. Mittal, MD & None & None & None & Radiation Oncology \\
\hline David G. Pfister, MD & $\begin{array}{l}\text { AstraZeneca Pharmaceuticals LP; Atara Biotherapeutics; } \\
\text { GlaxoSmithKline; Hookipa Pharma; Medlmmune Inc.; } \\
\text { Meira; Merck \& Co., Inc.; and Novartis Pharmaceuticals } \\
\text { Corporation }\end{array}$ & None & None & Medical Oncology, and Internal Medicine \\
\hline Harlan A. Pinto, MD & None & None & None & Medical Oncology, and Internal Medicine \\
\hline John A. Ridge, MD, PhD & None & None & None & Surgery/Surgical Oncology \\
\hline $\begin{array}{l}\text { James W. Rocco, MD, } \\
\text { PhD }\end{array}$ & None & None & None & Surgery/Surgical Oncology \\
\hline Cristina P. Rodriguez, MD & $\begin{array}{l}\text { Acerta Pharma; AstraZeneca Pharmaceuticals LP; Ayala } \\
\text { Pharmaceuticals; Bristol-Myers Squibb Company; } \\
\text { Genentech, Inc.; Incyte Corporation; Merck \& Co., Inc.; } \\
\text { Pharmacyclics, Inc.; Portola Pharmaceuticals, Inc.; and } \\
\text { Seattle Genetics, Inc. }\end{array}$ & Cue Biopharma & None & Medical Oncology \\
\hline Jatin P. Shah, MD, PhD & None & None & None & Surgery/Surgical Oncology \\
\hline Sharon Spencer, MD & None & None & None & Radiation Oncology \\
\hline Randal S. Weber, MD & None & None & None & Surgery/Surgical Oncology \\
\hline Gregory Weinstein, MD & None & None & None & Surgery/Surgical Oncology \\
\hline Matthew Witek, MD & None & Genzyme Corporation & None & Radiation Oncology \\
\hline Francis Worden, MD & $\begin{array}{l}\text { Bayer HealthCare; Bristol-Myers Squibb Company; Eisai } \\
\text { Inc.; Exelixis Inc.; IRX; Kura Oncology, Inc.; Loxo; Merck \& } \\
\text { Co., Inc.; Oragenics, Inc.; Pfizer Inc.; Rakuten; and Soligenix, } \\
\text { Inc. }\end{array}$ & Cue Biopharma, and Eli Lilly and Company & None & Medical Oncology \\
\hline Sue S. Yom, MD, PhD & None & None & None & Radiation Oncology \\
\hline Weining Zhen, MD & None & None & None & Radiation Oncology \\
\hline
\end{tabular}

The NCCN Guidelines Staff have no conflicts to disclose.
sThe following individuals have disclosed that they have an employment/governing board, patent, equity, or royalty:

Robert L. Foote, MD. Bionix: Elsevier; and Uney have

Antonio Jimeno, MD, PhD: Champions Oncology, Inc., and SuviCa, Inc.

Gregory Weinstein, MD: Olympus Corporation

Sue S. Yom, MD, PhD: Springer, and UpToDate 